\title{
Current and Emerging Magnetic Resonance-Based Techniques for Breast Cancer
}

\author{
Apekshya Chhetri ${ }^{1,2}$, Xin $\mathrm{Li}^{1}$ and Joseph V. Rispoli ${ }^{1,3,4 *}$ \\ ${ }^{1}$ Magnetic Resonance Biomedical Engineering Laboratory, Weldon School of Biomedical Engineering, Purdue University, \\ West Lafayette, IN, United States, ${ }^{2}$ Basic Medical Sciences, College of Veterinary Medicine, Purdue University, \\ West Lafayette, IN, United States, ${ }^{3}$ Center for Cancer Research, Purdue University, West Lafayette, IN, United States, \\ ${ }^{4}$ School of Electrical \& Computer Engineering, Purdue University, West Lafayette, IN, United States
}

\section{OPEN ACCESS}

Edited by:

Rabih Shakib Talhouk, American University of

Beirut, Lebanon

Reviewed by:

Alexander F. I. Osman, Al-Neelain University, Sudan Raja R. Narayan, Stanford University, United States

*Correspondence: Joseph V. Rispoli jrispoli@purdue.edu

Specialty section This article was submitted to Family Medicine and Primary Care,

a section of the journal

Frontiers in Medicine

Received: 15 April 2019 Accepted: 15 April 2020 Published: 12 May 2020

Citation:

Chhetri A, Li X and Rispoli JV (2020) Current and Emerging Magnetic Resonance-Based Techniques for Breast Cancer. Front. Med. 7:175. doi: 10.3389/fmed.2020.00175
Breast cancer is the most commonly diagnosed cancer among women worldwide, and early detection remains a principal factor for improved patient outcomes and reduced mortality. Clinically, magnetic resonance imaging (MRI) techniques are routinely used in determining benign and malignant tumor phenotypes and for monitoring treatment outcomes. Static MRI techniques enable superior structural contrast between adipose and fibroglandular tissues, while dynamic MRI techniques can elucidate functional characteristics of malignant tumors. The preferred clinical procedure-dynamic contrast-enhanced MRI-illuminates the hypervascularity of breast tumors through a gadolinium-based contrast agent; however, accumulation of the potentially toxic contrast agent remains a major limitation of the technique, propelling MRI research toward finding an alternative, noninvasive method. Three such techniques are magnetic resonance spectroscopy, chemical exchange saturation transfer, and non-contrast diffusion weighted imaging. These methods shed light on underlying chemical composition, provide snapshots of tissue metabolism, and more pronouncedly characterize microstructural heterogeneity. This review article outlines the present state of clinical MRI for breast cancer and examines several research techniques that demonstrate capacity for clinical translation. Ultimately, multi-parametric $\mathrm{MRI}$-incorporating one or more of these emerging methods - presently holds the best potential to afford improved specificity and deliver excellent accuracy to clinics for the prediction, detection, and monitoring of breast cancer.

Keywords: breast cancer, magnetic resonance, MRI, diffusion, spectroscopy, contrast

\section{INTRODUCTION}

The American Cancer Society has estimated that within the United States in 2020, a total of 276,480 females will be diagnosed with breast cancer and 42,170 are likely to die from the disease (1). While breast cancer treatment has advanced, early detection remains a principal factor for improved patient outcomes and reduced mortality. Although, mammography has been the standard method of breast cancer screening since the 1960s, magnetic resonance (MR) imaging (MRI) offers superior sensitivity, particularly within denser breasts, and an annual MRI exam is recommended for high-risk women (e.g., women with familial history, genetic predisposition, significant chest radiation history, or lobular cancer) (2). 
Amongst the existing and routinely practiced modalities to screen breast cancer, MRI has the highest sensitivity. In a recent study conducted over a period of eight years, Kuhl et al. reported a $95 \%$ confidence interval of $96.5-97.6 \%$ for specificity with a positive predictive value of $35.7 \%$ in diagnosing high grade breast tumors of sizes as small as $8 \mathrm{~mm}$ (3). A major limitation of clinical MRI lies in its wide range of specificity (37-97\%) manifested as failures in differentiating malignant breast tumors vs benign lesions (4-6). However, false positive results from MRI observed in high risk lesions differ significantly from the low risk lesions associated false positive results through radiographs (7). These inherent biological differences with significant prognostic implications cannot be overlooked as we compare the results between MRI and other radiographic screening modalities. The advancements in MRI techniques and future research summarized in this paper are aimed at overcoming the specificity associated limitation of MRI to differentiate benign lesions from aggressive breast tumors with improved accuracy.

At present, secondary breast cancer prevention for males is not emphasized as widely as in females owing to the low male breast cancer incidence rate of $1 \%(8,9)$. Studies demonstrating the use of MRI in screening male breast cancer patients are few, yet not uncommon (10-12). Survival outcomes of male breast cancer patients have worsened in recent years (12-14). The present treatment options for male breast cancer patients are derived from the clinical outcomes on female patients, which could be a potential limiting factor (14). Thus, more studies highlighting the impact of secondary breast cancer prevention on males, particularly given improved risk assessment from genetic testing, e.g., BRCA2-associated phenotype (15), are needed.

Advances in MRI and MR spectroscopy (MRS) have enabled clinicians to detect numerous biomarkers of breast cancer and to monitor the patient's response to chemotherapy. Studies have shown a correlation between these MR-based biomarkers and histopathological features of tumors. This linkage could provide a powerful technique for monitoring the progression of the disease and the patient's response to chemotherapy (16-21).

Image contrast based on tissue $T_{1}$ and $T_{2}$ are common MRI sequences exploiting the differences in the relaxation times of protons within the tissue under examination. $\mathrm{T}_{1}$ provides longitudinal relaxation time while $\mathrm{T}_{2}$ provides transverse relaxation time for a set of protons. By exploiting the distinct $T_{1}$ and $T_{2}$ relaxation properties of various tissues, static MRI provides superior structural contrast between adipose and fibroglandular tissues and remains a mainstay for risk analysis, tumor detection, and treatment monitoring. Dynamic MRI techniques go one step further, elucidating functional characteristics of malignant tumors. Dynamic contrast enhanced (DCE) MRI detects $\mathrm{T}_{1}$ changes in tissues over time immediately following bolus administration of a gadoliniumbased contrast agent; the hypervascularity of breast tumors results in altered uptake and washout rates, and the unique timeintensity curve can distinguish malignant from benign tumors. Recent concerns regarding lasting gadolinium accumulation and toxicity, however, have impacted patient's assent to undergo techniques requiring gadolinium-based contrast agent, including DCE MRI, and research efforts have renewed to design alternative, noninvasive methods. One leading contender is diffusion weighted imaging (DWI), which already has proven valuable as an adjunct to DCE by improving combined sensitivity. DWI can elucidate tissue properties based on the Brownian motion of water. Since diffusivity differs inside and outside cells, the pattern of tissue morphology can be established based on the restriction of motion of water molecules in densely packed cells (22). Emerging techniques including MRS and chemical exchange saturation transfer can shed light on underlying chemical composition, providing snapshots of tissue metabolism and characterizing microstructural heterogeneity. Furthermore, non-compartmentalized, non-Gaussian diffusion models have the potential to derive micrometer-scale diffusion metrics that may reflect tumor heterogeneity and microstructural dimensions. This review article outlines the various MRI techniques currently used for breast cancer and examines several research techniques that demonstrate capacity for clinical translation or potential to facilitate discoveries in basic research.

\section{CURRENT MR-BASED TECHNIQUES}

\section{Structural Imaging}

Among the clinical imaging modalities, MRI yields superior sensitivity of breast tumors and, notably among dense breasts, provides excellent contrast between tumor, adipose, and fibroglandular tissues $(23,24)$. A typical structural breast imaging protocol includes a $\mathrm{T}_{2}$-weighted sequence and a $\mathrm{T}_{1}$ weighted sequence, with and without fat suppression (25). Bilateral imaging is performed in order to evaluate asymmetries. High breast density is a known risk factor of developing malignant breast tumors (26), and specialized sequences have been developed for breast density measurement (27). The American College of Radiology Breast Imaging Reporting and Data System (BI-RADS) provides guidance for the succinct classification of overall breast composition, with emphasis on the proportion of fibroglandular tissues (25). As illustrated in Figure 1, fibroglandular tissues are readily differentiated from adipose tissues when using a $\mathrm{T}_{1}$-weighted sequence with fat suppression.

\section{Contrast-Enhanced Perfusion MRI}

Standard clinical breast MRI protocols also include a gadolinium dynamic contrast enhanced scan for distinguishing malignant from benign tumors. A fat-suppressed $\mathrm{T}_{1}$-weighted sequence is run before and up to 15 minutes after an intravenous bolus injection of gadolinium-based contrast agent followed by a saline flush. The rate of gadolinium washout is indicative of the microvascular properties and hyperintensity within malignant tumors is very sensitive and specific to malignant tumors (5). Notably, hormonal fluctuations can affect the uptake of gadolinium in healthy breast tissue, so dynamic contrast enhancement is only recommended to be performed during the first half of the menstrual cycle $(29,30)$. Representative dynamic contrast enhanced MRI are shown in Figure 2A.

In contrast to conventional dynamic contrast enhancement techniques, whole breast area (normal parenchymal breast tissues) can be enhanced utilizing the background parenchymal 

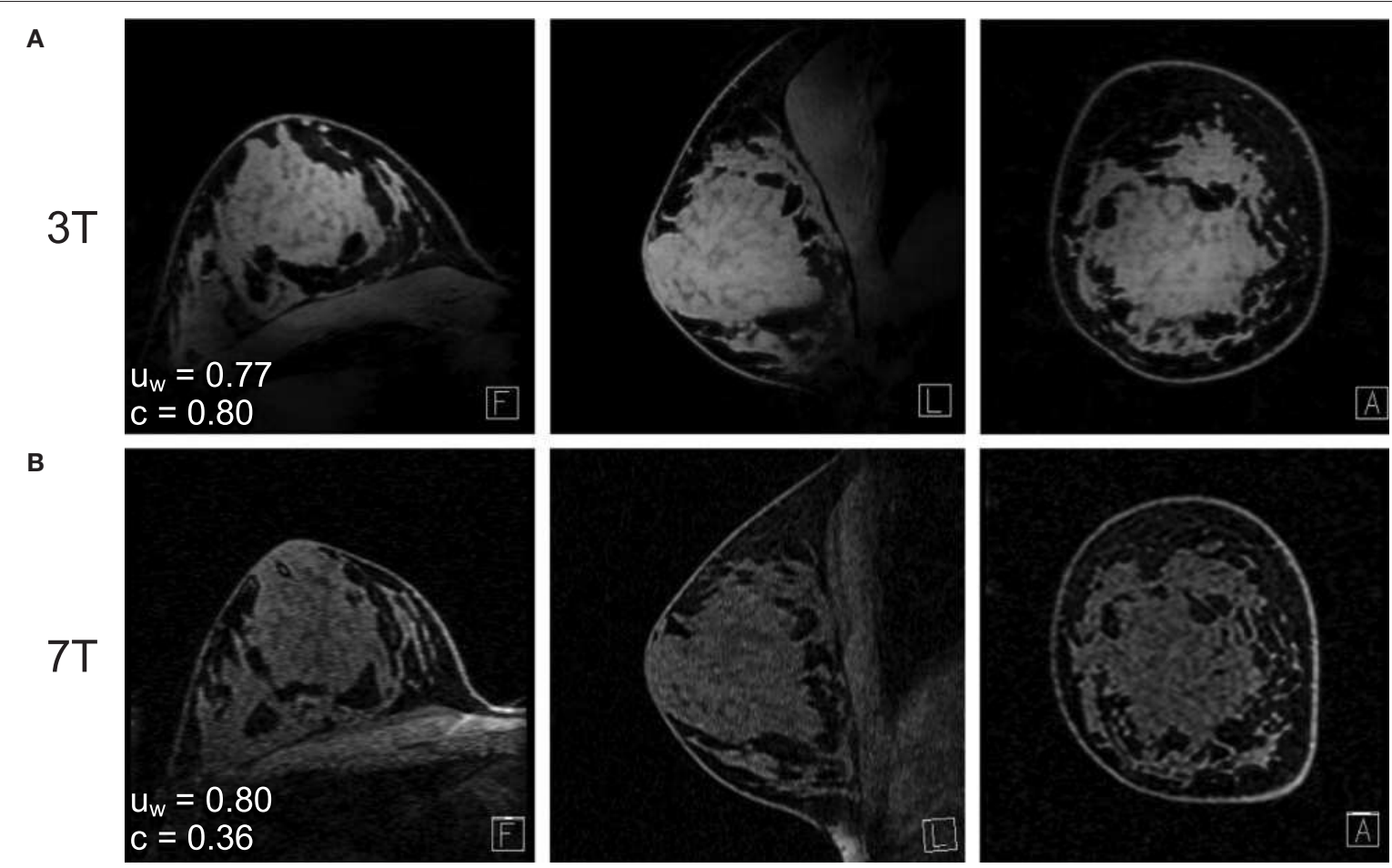

FIGURE 1 | Fat-suppressed $\mathrm{T}_{1}$-weighted MRI of the same subject at (A) $7 \mathrm{~T}$ and (B) 3T. The water signal uniformity $\left(\mathrm{U}_{\mathrm{w}}\right)$ is similar across $3 \mathrm{~T}$ and $7 \mathrm{~T}$, while the fat-water contrast (c) is markedly improved at 7T. Reprinted with permission from Brown et al. (28); ${ }^{\odot} 2013$ Wiley Periodicals, Inc.

enhancement (BPE) technique. This technique can identify specific regions of differences within normal mammary tissues over others which facilitates a wider prediction of the tumor microenvironment and its possible changes. These features augment the specificity and sensitivity of MRI and is advantageous in reducing false positive results. BPE is assessed by four qualitative BI-RADS categories: minimal $(<25 \%$ of glandular tissue demonstrating enhancement), mild (25-50\% enhancement), moderate (50-75\% enhancement), or marked (> $75 \%$ enhancement). In 2011, King et al. concluded that increased BPE is strongly predictive of breast cancer odds (32), however more recent studies have found no correlation with positive biopsy rate, sensitivity, or specificity (33).

\section{Clinical MR Scanners}

Clinical 1.5 tesla (T) and 3T scanners typically include a builtin body coil for transmitting radiofrequency (RF) pulses, i.e., the $B_{1}$ field. Given the off-center positioning of the breasts within the body coil, and the asymmetric loading presented by the torso, transmit $B_{1}$ inhomogeneity is prone to worsen at higher magnetic fields. At 3T, the body coil has been reported to produce up to $50 \%$ error in tip angle (34), which significantly confounds the accuracy of quantitative image-derived measures including DCE enhancement ratio (35) and $\mathrm{T}_{1}$ mapping (36). These issues may be mitigated using advanced quantification techniques and accompanying pulse sequences, e.g., saturationrecovery snapshot-fast low angle shot (37).
Irrespective of the scanner's magnetic field strength, receive array coils improve signal-to-noise ratio (SNR) throughout the breast compared to utilizing the body coil to receive the RF signal (38). A variety of commercial breast receive array coils are available $(39,40)$ and custom $3 \mathrm{~T}$ array coils have been reported to further improve performance for specific applications $(41,42)$.

\section{EMERGING MR-BASED TECHNIQUES}

\section{Diffusion-Weighted MRI}

\section{Gaussian Models}

\section{Diffusion weighted imaging}

As a noninvasive MRI technique, diffusion weighted imaging (DWI) detects the bulk diffusion of water within tissue and offers substantial advantages in visualizing and differentiating tumors based on their vascularization patterns. The amount of diffusion weighting applied to the MRI signal is set by the operator-defined $\mathrm{b}$-value, with zero indicating no diffusion weighting (Figure $\mathbf{3 A}$ ) and commonly employed b-values for breast DWI being on the order of $1,000 \mathrm{~s} / \mathrm{mm}^{2}$. DWI encodes water diffusion in one to three orthogonal directions (each direction corresponding to a gradient direction) and assumes unrestricted isotropic diffusion. The resulting apparent diffusion coefficient (ADC) quantifies the mean bulk diffusion per pixel and is an established quantitative surrogate for tissue cellularity. While the cell membranes and vascularity within tumors preclude unrestricted water motion, the simple DWI model 


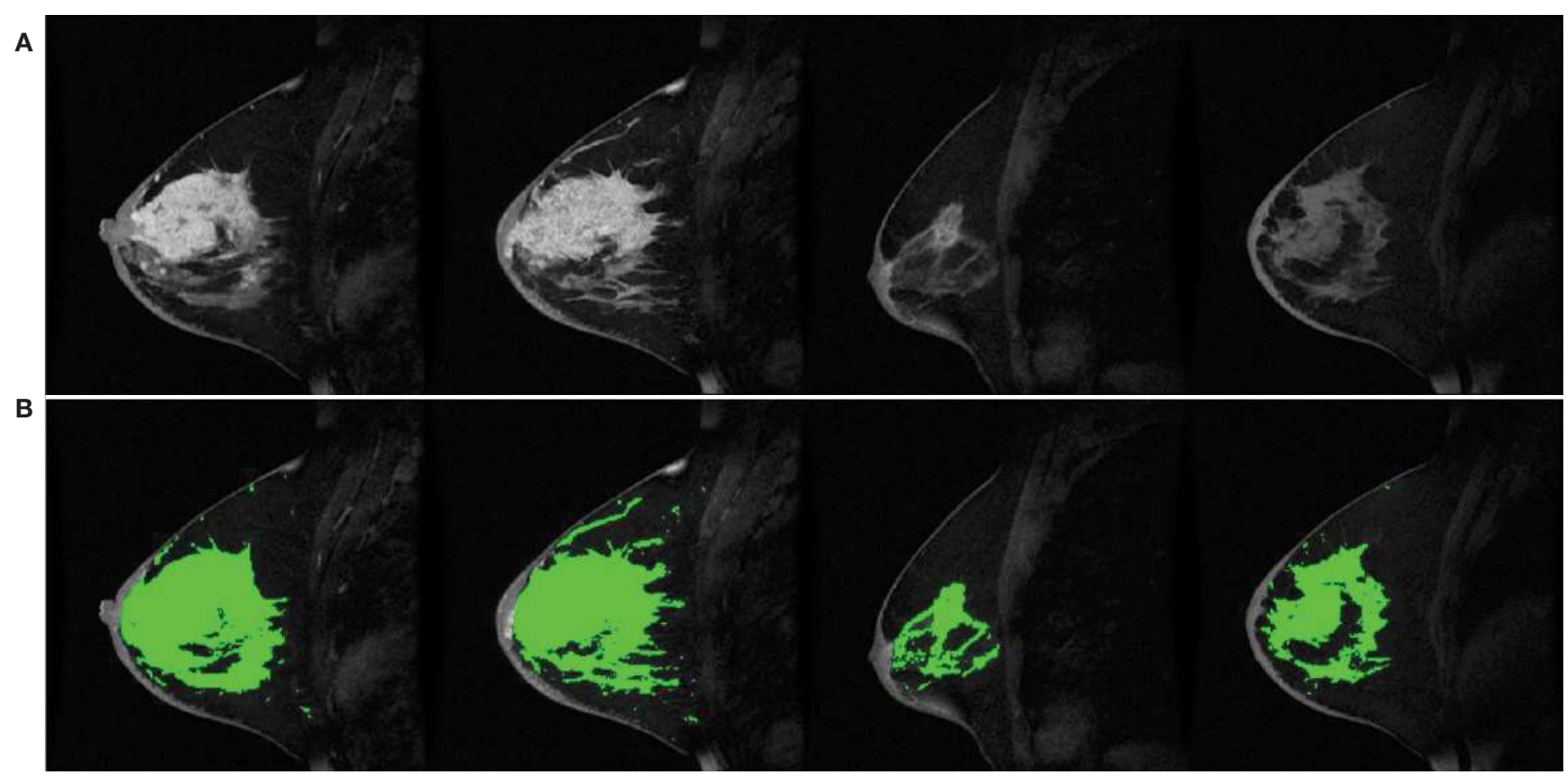

FIGURE 2 | High-resolution 1.5T DCE MRI of four subjects from the American College of Radiology Imaging Network (ACRIN) 6657 repository (31) (A) unmodified and $\mathbf{B}$ ) with the segmented breast fibroglandular tissue overlaid in green.

accurately represents voxels (single data-specific locations on a 3D tissue construct) with high water content and low cell density and the resulting hypo intensity within breast tumors remains informative. This effect is illustrated in Figure 3B. Moreover, a technique known as automated DWI, which retrospectively computes higher b-value images from the typical DWI acquisitions, has been shown to improve lesion detection, particularly when calculations are performed on a voxel-wise basis (44).

Traditional spin-echo DWI relies on a conventional singleshot echo planar imaging readout prone to produce ghosting artifacts that hinder image quality. Other readouts such as spatiotemporal encoding mitigate ghosting artifacts at the expense of added noise (45). Ultimately, readout-segmented (or multi-shot) echo planar imaging has been established as a robust solution with good sensitivity; ghosting artifacts are prevented since each shot acquires the full extent of $\mathrm{k}$-space in the phase-encode direction but only traverses a segment in the readout direction (46). The readout-segmented DWI sequence is prevalent and frequently prescribed for bilateral breast DWI with 2-mm inplane resolution.

Higher-resolution DWI may be attained by reducing the field of view, which focuses on a target region within the breast. With this technique, $0.8-\mathrm{mm}$ in-plane resolution can be resolved at $3 \mathrm{~T}$, and the resulting ADC maps provide greater detail facilitating the assessment of tumor morphology (47). Imaging time can be reduced by combining the high-resolution reduced field of view approach with multiband RF excitation (48).

Obtaining consistently high-quality breast DWI is one of the challenges that current studies are targeting to overcome. The American College of Radiology Imaging Network (ACRIN)
6698 clinical trial has shown that ADC can be measured with excellent repeatability and reproducibility in a multi-institution setting using a standardized protocol and QA procedure (49). An MRI platform that can provide a clearer distinction between tumors delivers more deterministic results to the patients, thus restricting the number of unnecessary biopsies performed on patients largely due to false positive results. However, it is important to note DWI should not be used as a stand-alone clinical protocol; rather, DWI hold a compelling role within multi-parametric MRI (mpMRI) protocols. For example, DWI detects significantly fewer cancers compared to dynamic contrast enhancement technique, but when incorporated as an adjunct it will yield superior sensitivity (46). Similar improvements can be achieved when pairing DWI with other complementary techniques such as MRS, as discussed later.

\section{Diffusion tensor imaging}

Diffusion tensor imaging (DTI) builds on the DWI technique by increasing the number of diffusion-encoding directions, thus enabling the calculation of anisotropic diffusion. While DWI characterizes isotropic diffusion within each voxel as a sphere, DTI employs at least six gradient directions and geometrically represents anisotropic diffusion within each voxel as an ellipsoid. The diffusion tensor, a matrix of directional diffusion coefficients, is established for each voxel based on the diffusion rates detected concurrent with each gradient configuration. Given the directionality of resulting diffusion information, DTI can provide additional insight into tissue microstructure through mean diffusivity-the DTI analogue to the ADC in DWI-and various anisotropy measures which provide critical 

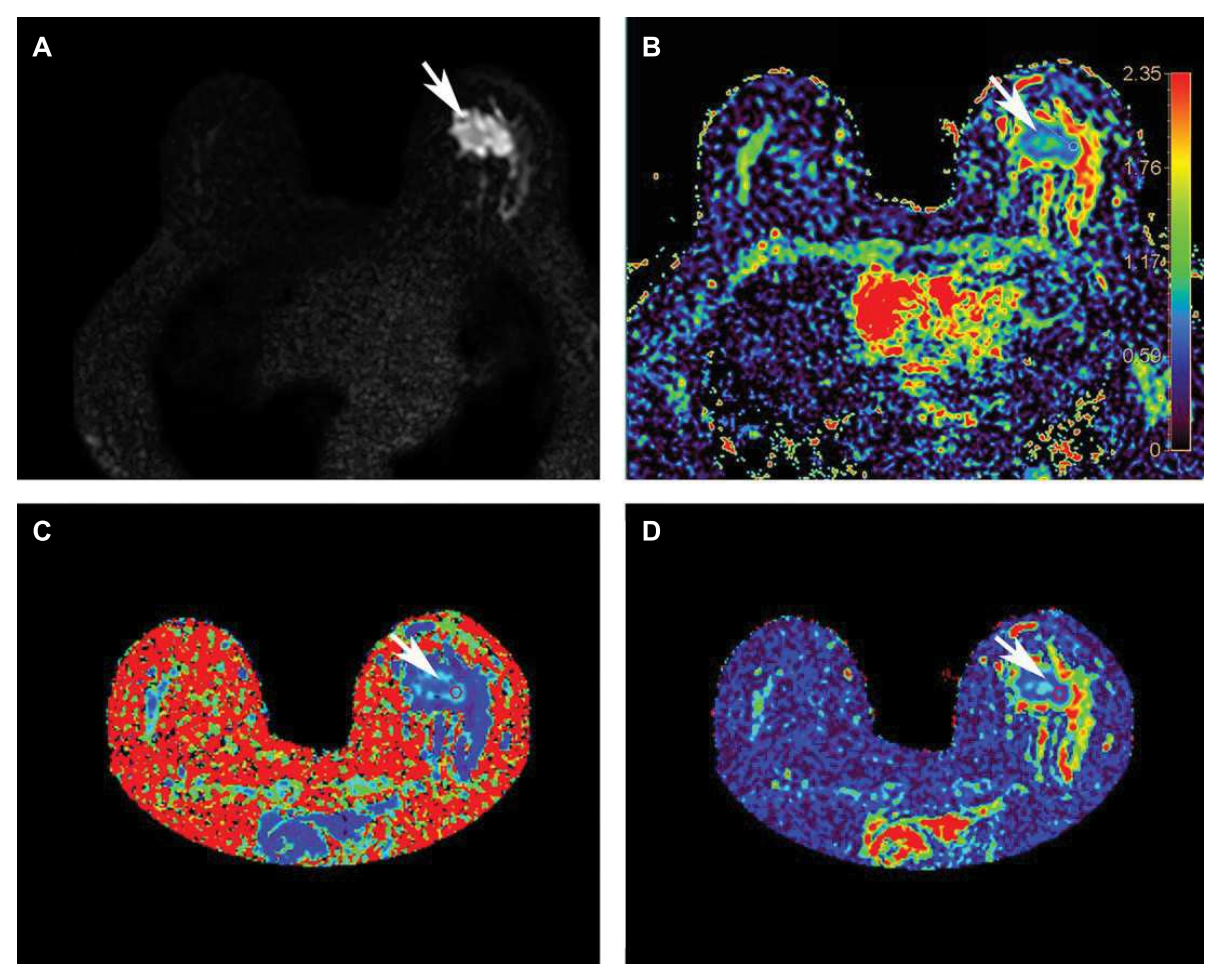

FIGURE 3 | A comparison of diffusion techniques and metrics from scanning a 57-year-old woman with left breast invasive ductal carcinoma (tumor indicated by the arrow) at 3T. (A) The baseline $b=0$ image acquired without diffusion gradients; (B) conventional DWI: apparent diffusion coefficient (ADC) map (scale bar 0-2.35 $\mathrm{mm}^{2} / \mathrm{s}$ ), arrow indicating tumor ADC value of $1.090 \mathrm{~mm}^{2} / \mathrm{s}$; (C) diffusion kurtosis imaging: mean kurtosis map (scale bar 0-3 mm²/s), arrow indicating tumor mean kurtosis value of $1.154 \mathrm{~mm}^{2} / \mathrm{s}$; (D) DTI: mean diffusivity map (scale bar 0-2.8 $\mathrm{mm}^{2} / \mathrm{s}$ ), arrow indicating tumor mean diffusivity value of $0.808 \mathrm{~mm} / \mathrm{s}$. Reprinted with permission from Li et al. (43); ${ }^{\circledR} 2018$ International Society for Magnetic Resonance in Medicine.

information such as a tissue's vascularity, density, and cellular features. Such anisotropic features include fractional anisotropy, radial anisotropy, the individual diffusion coefficients, and the maximal anisotropy index. A mean diffusivity map is shown in Figure 3D.

While there is a consensus across studies that mean diffusivity is significantly lower in malignant tumors compared to benign lesions, there are conflicting results regarding the diagnostic utility of the anisotropy indices (50). Some reports suggest the standard DTI metrics of fractional anisotropy, radial anisotropy, and mean diffusivity cannot differentiate healthy tissue from cancer, while the diffusion coefficients and absolute maximal anisotropy index can assist in differentiating malignant tumors from both benign lesions and healthy tissue $(51,52)$. A recent approach suggests modifying the DTI model by compartmentalizing the diffusion signal as a combination of an anisotropic diffusion tensor (stroma cells) and a spectrum of highly-restricted (lymphocytes), restricted (cancer cells), and hindered (edema) isotropic-diffusion tensors; initial results with this modified diffusion basis spectrum imaging technique indicate greater diagnostic sensitivity and specificity distinguishing between malignant tumors and benign lesions (53).

Remarkably, DTI metrics have been shown to have distinctive correlations with breast cancer subtypes. Onaygil et al. found statistical significance between several anisotropy indices in estrogen receptor positive and negative (ER+ and ER-) breast cancers, and separate correlations with the levels of $\mathrm{Ki}$ 67, a biomarker for cellular proliferation, while Ozal et al. reported identifying distinct correlations between various DTI metrics and levels of breast cancer prognostic factors: ER, progesterone receptor (PR), human epidermal growth factor receptor 2 (HER2), Ki-67, and lymphatic invasion in invasive tumors $(54,55)$.

The challenge of achieving excellent repeatability and reproducibility across sites remains ongoing with breast DTI. Studies indicate the ADC can be reproduced with more accuracy compared to DTI anisotropy metrics such as fractional anisotropy $(56,57)$.

Notably, the technical development that drove substantial improvements into the DTI technique was largely motivated by the quest to map neuronal tracks of white matter in the brain. Preliminary studies reconsidering the utility of DTI for breast cancer have investigated utilizing DTI for breast tractography (58). Given the stark difference between the twopoint connections of neuronal tracks and the branching ductal tree, Degani and colleagues proposed a novel computational methodology of post-processing DTI data using vector maps and clustering to infer the detailed structure of the mammary tree $(59,60)$. 


\section{Non-gaussian Models \\ Diffusion kurtosis imaging}

While a Gaussian distribution of diffusion indeed applies to pure liquids and gels, barriers from complex tissue structures in effect modify the probability distribution of diffusion. Accordingly, the statistical metric for quantifying the actual probability distribution within tissue is designated as kurtosis. By acquiring additional, higher b-value images (where b value is an operatordefined parameter correlating with the strength and time for diffusion in imaged tissues), on the order of $b=1000-3000$ $\mathrm{s} / \mathrm{mm}^{2}$, and at least 15 diffusion gradient directions, the diffusion kurtosis imaging technique can map multiple structures within a single voxel, e.g., crossing white matter fibers in the brain. In the context of breast imaging, diffusion kurtosis imaging is sensitive to intracellular structures such as membranes and organelles (61) and, in addition to a mean kurtosis map, can provide a diffusion heterogeneity index sensitive to the tumor microstructure (62). Importantly, diffusion kurtosis analysis of the breast improves with correction for unsuppressed fat signal (63). A mean kurtosis map is shown in Figure 3C.

\section{Intravoxel incoherent motion}

While technically also a perfusion imaging method, the intravoxel incoherent motion model adds additional quantitative terms to account for microvascularity. Accordingly, intravoxel incoherent motion has the potential to discern both tissue diffusivity and microcapillary perfusion without the need for contrast agents (64). Additional quantitative metrics include the perfusion fraction (or blood volume fraction of vasculature) and a pseudodiffusion coefficient corresponding to water movement within microvasculature. For breast cancer imaging, the intravoxel incoherent motion model is more often added to non-Gaussian diffusion methods (65). A combination of high perfusion fraction, high kurtosis, and low diffusion coefficient is often observed at the periphery of tumors, while the opposite pattern is apparent in the necrotic core as well as within fibroadenomas (66). Accordingly, the intravoxel incoherent motion model shows promise for differentiating between malignant and benign breast lesions $(67,68)$. Furthermore, a recent report also indicates histogram analysis can accurately predict neoadjuvant chemotherapy (NAC) response (69).

\section{Other Diffusion Models}

Many other advanced diffusion methods have been proposed with the goal of probing intravoxel heterogeneity and cellularity; a review of several such methods and their suitability for cancer imaging was recently published by Tang and Zhou (62). Generally, these methods require additional acquisitions with bvalues up to $4000 \mathrm{~s} / \mathrm{mm}^{2}$, presenting a challenge given the lower SNR inherent with high b-value acquisition.

\section{Magnetic Resonance Spectroscopy Proton Spectroscopy}

Magnetic resonance spectroscopy (MRS) provides a localized snapshot of the biochemical makeup of tissue (70). Proton $\left({ }^{1} \mathrm{H}\right)$ MRS offers the greatest sensitivity and simplest data acquisition. Elevated levels of choline-containing compounds indicate cell membrane turnover and are a biomarker for malignant breast tumors (71). All choline-containing compounds are quantified as total choline (tCho) and appear as a peak at $3.2 \mathrm{ppm}$ on the ${ }^{1} \mathrm{H}$ MRS spectrum. A thorough 2013 meta-analysis of tCho studies ( $n=1193$ patients) suggests this biomarker offers $73 \%$ sensitivity and $88 \%$ specificity (72). Moreover, high levels of glutathione measured with ${ }^{1} \mathrm{H}$ MRS have been associated with increased resistance of cancer cells to radiation-induced cell death (73).

The recent ACRIN 6657 MRS clinical trial aimed to predict response to NAC with tCho single-voxel MRS; the results were inclusive, with only 29/119 subjects providing useable data (74). A primary limitation of the protocol was the manual placement of the MRS voxel within or encompassing the tumor, leading to issues with reproducibility across clinical sites. In the future this limitation can be addressed by running a full 3D magnetic resonance spectroscopic imaging sequence, allowing localized analysis to be performed retrospectively.

The high specificity of tCho studies suggests ${ }^{1} \mathrm{H}$ MRS could be an effective addition to a mpMRI protocol (75). For superior differentiation of benign tumors from normal physiology, ADC values from DWI in combination with tCho peaks can provide a comprehensive result (76).

Proton MRS also facilitates lipid analysis, i.e., proportions of mono- and poly-unsaturated fats, fatty acid chain length, and mean saturation, all measures that are sensitive to past dietary intake. Specific lipid signatures have been reported to be significantly lower in malignant versus benign tumors, and luminal cancers can be differentiated via lipid MRS (7779). Acquisition issues stemming from water-lipid susceptibility boundaries can be avoided by running a zero-quantumcoherence 2D MRS sequence (80).

\section{Multinuclear Spectroscopy}

With ${ }^{1} \mathrm{H}$ MRS, many spectral peaks overlap and potentially mask lower-concentration metabolites. While multinuclear MRS suffers upfront from reduced sensitivity-an inherent deficit in SNR that is somewhat mitigated at higher fields-they provide a window into breast cancer metabolism with information inaccessible to ${ }^{1} \mathrm{H}$ MRS (81). Phosphorus-31 $\left({ }^{31} \mathrm{P}\right)$ MRS separates distinct choline compounds, specifically phosphorylcholine and glycerophosphocholine, otherwise overlapped as tCho on the ${ }^{1} \mathrm{H}$ spectrum. The role of phosphocholines in breast cancer metabolism is of broad interest (82-85), with the ratio of phosphocholine to glycerophosphocholine hypothesized to switch from low to high during malignant transformation (86), and to increase further with tumor progression (87). The ratio of phosphomonoesters to phosphodiesters has been shown to decrease after successful NAC (88). An example ${ }^{31} \mathrm{P}$ spectrum from an ER+, PR+, HER2- tumor is presented in Figure 4.

Carbon-13 $\left({ }^{13} \mathrm{C}\right)$ MRS can provide additional information such as the composition of breast fat and correlations that may predispose to cancer. Performing in vivo ${ }^{13} \mathrm{C} \mathrm{MRS}$ is difficult for many reasons, including low natural abundance, low (in comparison to ${ }^{1} \mathrm{H}$ ) sensitivity, J-coupling bonds between ${ }^{1} \mathrm{H}$ and ${ }^{13} \mathrm{C}$ atoms that obfuscate spectral peaks, and unique hardware instrumentation requirements. The preferred ${ }^{13} \mathrm{C}$ MRS experiment, applying broadband proton decoupling, requires 
A

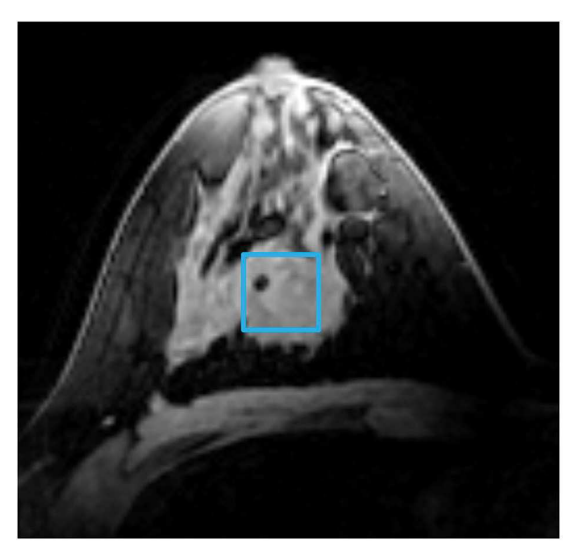

B

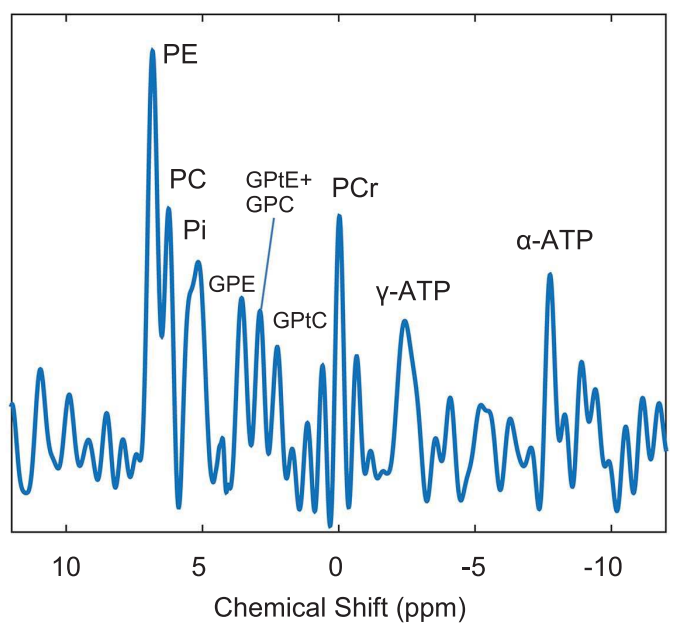

FIGURE 4 | Example $7 \mathrm{~T}$ data of a patient with an $\mathrm{ER}+, \mathrm{PR}+, \mathrm{HER} 2$ - tumor. (A) $\mathrm{T}_{1}$-weighted image with indicated voxel selection (blue square), (B) ${ }^{31} \mathrm{P}$ MRS spectrum of nine fitted metabolites. Adapted from Krikken et al. (88), used under CC BY.

RF coils operating at both the ${ }^{1} \mathrm{H}$ and ${ }^{13} \mathrm{C}$ frequencies; the ${ }^{1} \mathrm{H}$ channel is used for scout imaging as well as to transmit proton-decoupling pulses across the J-coupled chemical shift band (89). By employing proton decoupling at 7T, natural abundance ${ }^{13} \mathrm{C}$ lipid analysis from the breast was demonstrated (90). Enriched or hyperpolarized ${ }^{13} \mathrm{C}$ studies boost the SNR and facilitate additional studies, including using ${ }^{13} \mathrm{C}$-labeled choline to distinguish between catabolic and anabolic pathways in choline metabolism (91), and gauging glucose metabolism in the breast using $\left[\mathrm{U}_{-}{ }^{13} \mathrm{C}\right]$ glucose bolus injection (92).

\section{Magnetization Transfer}

Magnetization transfer (MT) was first introduced by Wolff and Balaban (93); the MT image contrast reflects the exchange of magnetization between protons in free water and protons bound to macromolecules due to chemical exchange and dipole-dipole interactions. After image acquisition with a specialized offresonance RF pulse, the MT effect among voxels of interest is quantified using either the so-called $z$-spectrum or a histogram of the MT ratio. The repeatability of quantitative breast MT measurements among cohorts of healthy volunteers has recently been demonstrated $(94,95)$. MT images can provide important information of tumor response to NAC (96). Chemical exchange saturation transfer extends the capabilities of MRS by indirectly detecting low-concentration chemicals through their proton exchange with water, including protein aggregates in malignant tumors. For example, amide proton transfer imaging detects the protein and peptide concentration by saturating the amide protons within peptide bonds. Dula et al. defined an integrated voxel-wise metric assumed to reflect the cellular protein and peptide content, designated amide proton transfer residual, and calculated this measure before and after neoadjuvant chemotherapy for two women with ER- breast cancer who experienced contradictory outcomes (95). As illustrated in Figure 5, they found a decrease in amide proton transfer residual from the woman with a complete response, while the metric from the woman with progressive response increased (95). Moreover, chemical exchange saturation transfer can discriminate between nonmalignant and aggressive human breast cancer cells, as it can characterize the metabolites altered by breast cancer cell aggressiveness and chemotherapy response (97). For example, the amide proton transfer signal in triple negative tumors is distinct and may result from the unique microenvironment of the tumor subtype (98). In addition, amide proton transfer asymmetry is observed in patients with breast cancer treatmentrelated lymphedema (99). Notably, high quality amide proton transfer images can be readily obtained at $7 \mathrm{~T}$, because both the chemical exchange saturation transfer effect and SNR are enhanced at higher field strengths (100).

\section{Other Techniques}

\section{Sodium MRI}

Sodium $\left({ }^{23} \mathrm{Na}\right)$ is abundant in the body and, unlike other nonproton nuclei that yield spectra for chemical quantification, sodium has no chemical shift dispersion and instead produces images (101). Malignant tumors are thought to increase sodium content due to disruption of the sodium-potassium pump in cell membranes. Elevated tissue sodium concentration has been confirmed in malignant lesions (102), and sodium concentration correlates well with the ADC of DWI (103).

\section{Susceptibility Weighted Imaging}

Historically recognized as the cause of frequent MRI artifacts, particularly near air-tissue interfaces or in the vicinity of metal implants, differences in magnetic susceptibility can also produce contrast between diamagnetic and paramagnetic tissues. Ductal carcinoma in situ (DCIS) is frequently missed by DCE MRI and has been shown to associate with certain patterns of breast calcifications (104). Calcium is more diamagnetic than tissue water, and the susceptibility effects are intensified 


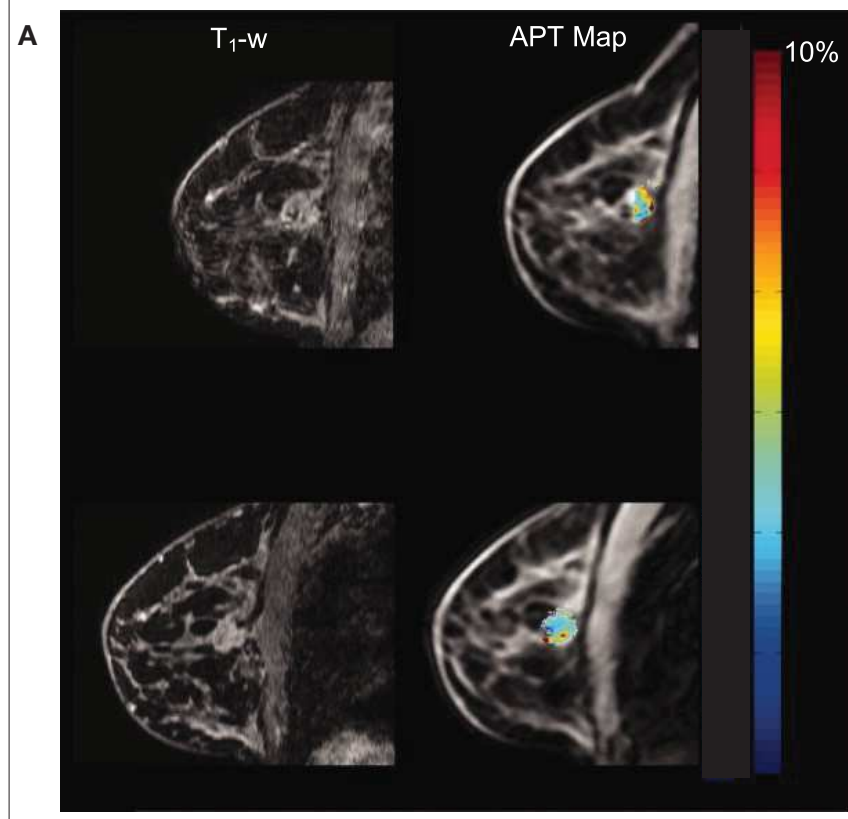

B

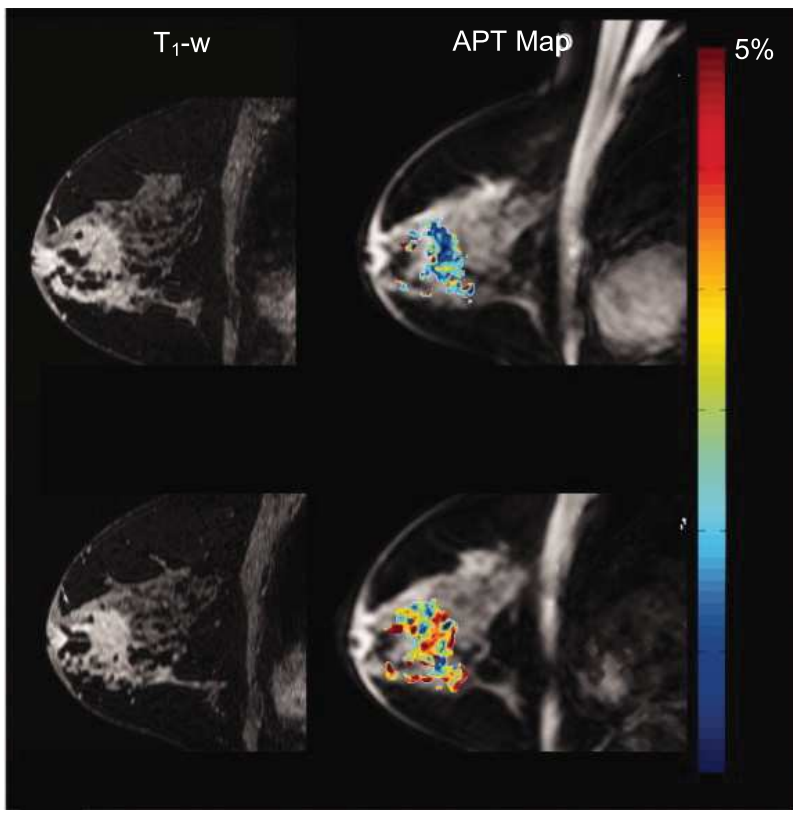

FIGURE 5 | Amide proton transfer maps overlaying anatomical $T_{1}$-weighted images acquired at 3 T. The top row shows data acquired prior to neoadjuvant chemotherapy (NAC); the bottom row shows data acquired after one cycle of NAC. (A) Patient who had complete response (i.e., no residual tumor) and (B) patient who had progressive disease. Reprinted with permission from Chan et al. (95); ${ }^{\circledR} 2012$ Wiley Periodicals, Inc.

at higher magnetic fields. Figure 6 illustrates the ability of 7T susceptibility-weighted MRI to identify microcalcifications otherwise only visible using mammography (105).

\section{MR Elastography}

MR elastography (MRE) images a low-frequency acoustic wave as it propagates throughout tissue. By calculating the local complex

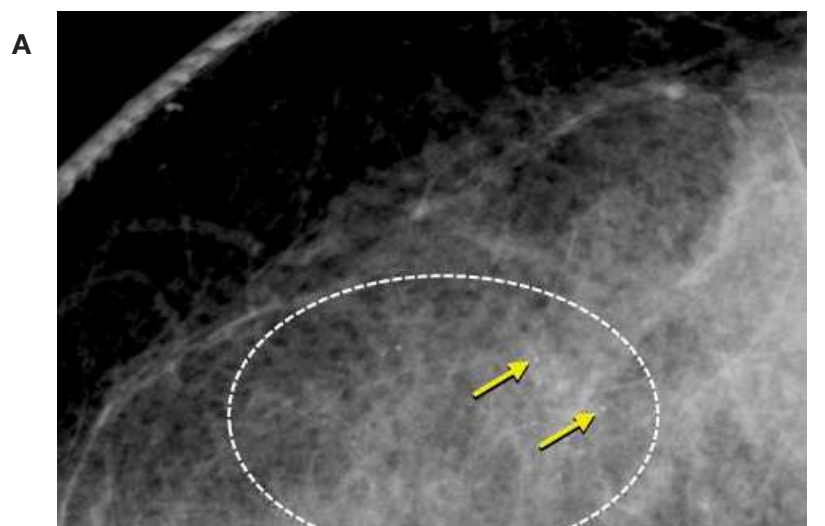

B

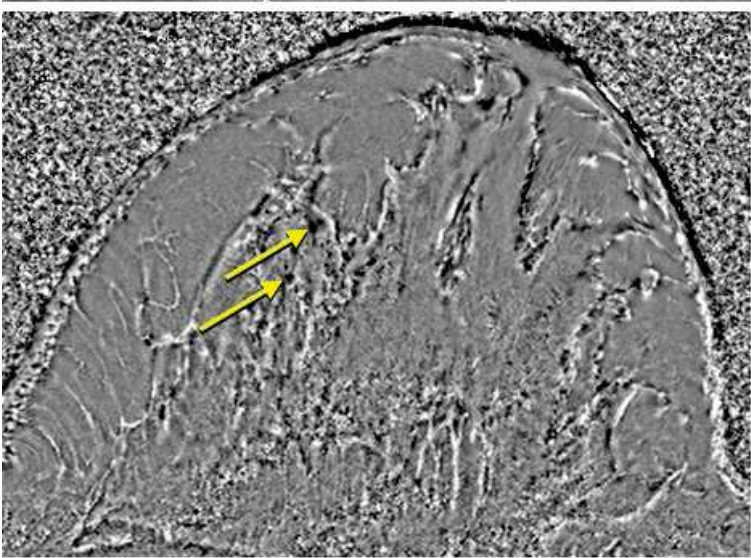

C

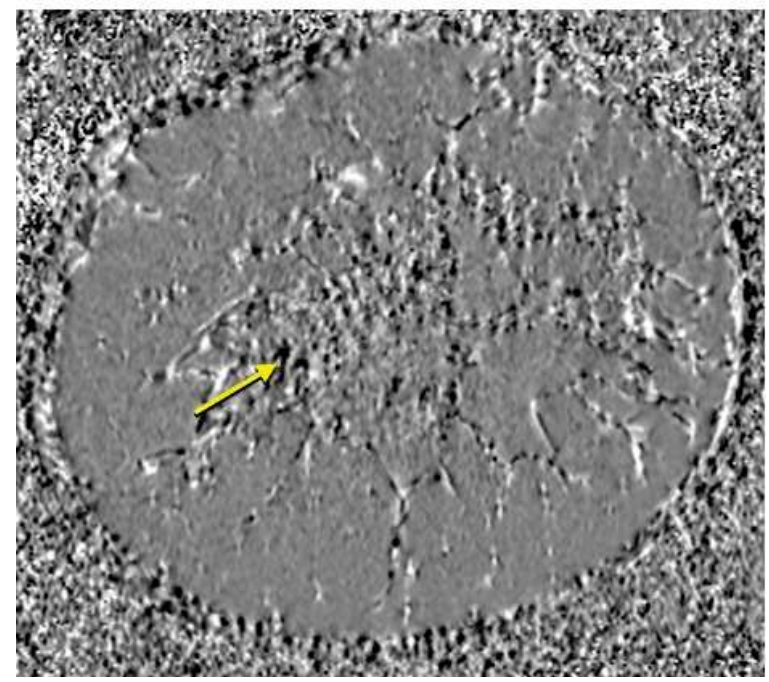

FIGURE 6 | Comparison of (A) mammogram and (B,C) susceptibility weighted phase images acquired at $7 \mathrm{~T}$ with a $0.35-\mathrm{mm}$ isotropic resolution $\mathrm{T}_{2}^{*}$-weighted 3D gradient echo sequence (105). Diamagnetic microcalcifications are indicated by yellow arrows and are hypointense in the susceptibility weighted phase images.

sheer modulus, MRE can characterize biomechanical properties of breast tissue including differences in stiffness. The initial aim of employing MRE for breast cancer was to differentiate benign lesions from malignant tumors; the more liquid-like behavior of 

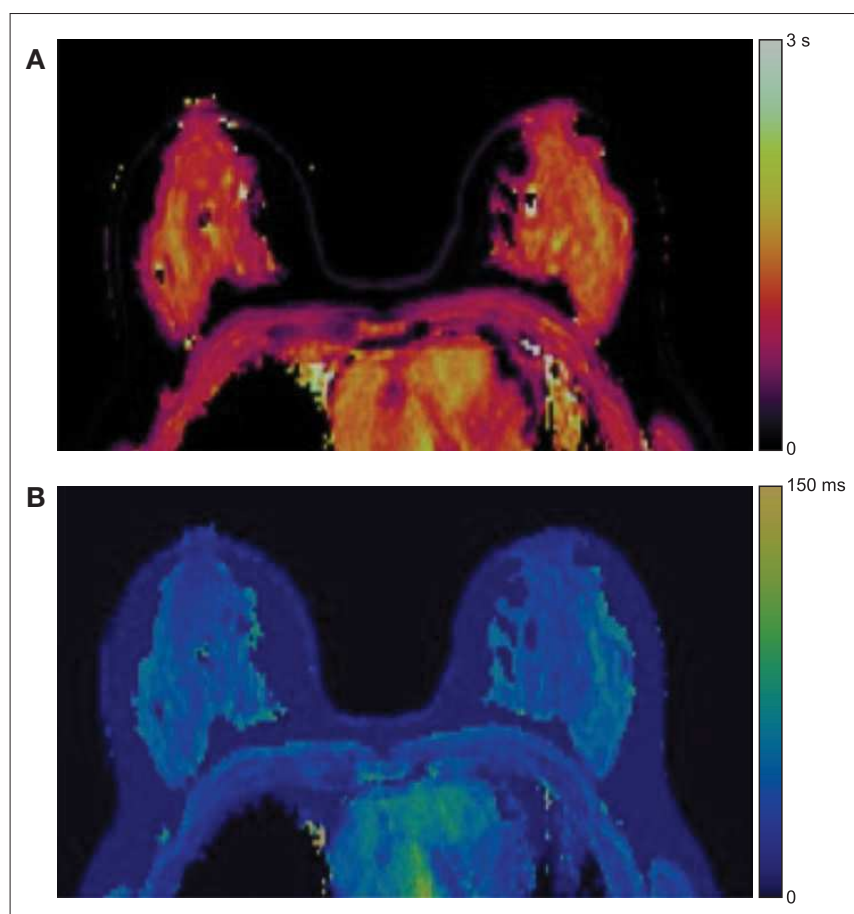

FIGURE 7 | Example MR fingerprinting of the breast. Representative (A) $T_{1}$ and (B) $T_{2}$ MR fingerprinting color maps from one subject. Reprinted with permission from Chen et al. (109); ${ }^{\circledR} 2019$ International Society for Magnetic Resonance in Medicine.

malignant tumors provided sufficient MRE contrast to achieve this aim (106). More recently, MRE is being combined with $3 \mathrm{D}$ strain imaging, the latter altering the stress-load relation of tumors; ongoing studies are investigating the potential of MRE to determine mechanical forces to estimate the metastatic potential of tumors (107).

\section{MR Fingerprinting}

A relatively new technique known as MR fingerprinting utilizes a pseudorandom RF excitation and pattern recognition to produce quantitative maps of tissue properties (108). Results from preliminary breast MR fingerprinting studies illustrate the simultaneous quantitative mapping of $\mathrm{T}_{1}$ and $\mathrm{T}_{2}$ in a bilateral configuration $(109,110)$. Representative $\mathrm{T}_{1}$ and $\mathrm{T}_{2} \mathrm{MR}$ fingerprinting maps are shown in Figure 7.

\section{MR Electrical Properties Tomography}

MR electrical properties tomography exploits typically undesirable distortions in the RF transmit field $\left(B_{1}\right)$ to reconstruct the conductivity and electrical permittivity of tissue (111). A preliminary breast MR electrical property tomography study by Shin et al. found malignant cancers have higher conductivity than benign lesions, and invasive cancers showed higher conductivity compared to DCIS (112).

\section{Novel Contrast Agents}

Recent discoveries of gadolinium retention within the body have raised questions regarding the long-term toxicity of gadoliniumbased contrast agents and propelled the quest for novel contrast agents that are both safe and equally effective (113). Recent studies have begun reevaluating alternative contrast agents for breast cancer, including manganese $(114,115)$ and iron chelates (116). Even so, research continues on gadolinium-based contrast agent's improvements, and agents can be designed to target specific molecular peptides. A preclinical study utilized one such contrast agent to bind to fibrin-fibronectin complexes abundant in malignant cancer, including micro metastases (117). While human trials have not commenced, these novel contrast agents have potential to improve the early detection and characterization of high-risk breast tumors.

\section{Machine Learning}

Machine learning is a branch of data science that "trains" computers to learn data without preprograming the computers to perform specific tasks. There are two types of machine learning models: unsupervised learning and supervised learning. Unsupervised learning aims to classify data that have not been assigned labels or categories; examples include neural networks and clustering to map input data (e.g., breast images) into output categories that share similar contents (e.g., tumor assessments). On the other hand, supervised learning aims to classify data that have been assigned with ground truth labels (e.g., radiological assessments); example models include regression methods and support-vector machines (SVM).

As an artificial intelligence tool, machine learning may best be introduced to the clinic through structured use cases; in the case of breast cancer, these may include the application of artificial intelligence to identify suspicious microcalcifications (118) and, given the variability of visual density assessments (119), the quantification of breast fibroglandular tissue volume (25). The American college of radiology recommend using the BI-RADS categories for characterizing breast lesions. This method relies on the radiologist's experience and is limited by inter-observer variance.

Neural networks are machine learning models that consist of multiple interconnected layers. The study of neural networks is termed deep learning. Lately, deep learning has surpassed traditional image processing models in the segmentation and detection of novel imaging biomarkers (120). Convolutional neural networks are a type of neural network that has convolutional layers and hidden layers, and they have profound diagnostic performance. For example, a 3D deep convolution neural network can be used to identify and localize malignant breast lesions in DCE images, previously demonstrating 90.8\% sensitivity and $69.3 \%$ specificity $(121,122)$. Another potential application is fibroglandular tissue and BPE assessment; while BI-RADS defines relevant categories, it does not establish percentage values for their quantification. A large proportion of fibroglandular tissue in the breast correlates with breast cancer risk $(23,26,119,123)$. Robust fibroglandular tissue quantification can be an efficient tool for clinicians to process large amount of breast MRI data and support more accurate breast cancer 
risk assessments (124). Independent of fibroglandular tissue quantification, computer-aided BPE quantification in DCE images has shown potential to be an imaging biomarker of breast cancer (125). For breast image segmentation and tumor volume quantification, several algorithmic routines have been demonstrated, e.g., (123, 124, 126-128); however, deep computational neural networks (i.e., U-nets) have shown particular promise for improving robustness and accuracy of results (129-131). Figure 2B shows the segmented fibroglandular tissue overlaid on anatomical DCE breast images. Based on fully automated computerized approaches, BPE DCE-MRI recently has been reported applicable in screening potential risk factors of breast cancer to regionalize the parenchymal tissues and their vasculature (125).

Radiomics involves extracting quantitative features from medical images, such as tumor size, shape, and textures, and patient-level data, such as the genetic data, to determine the underlying relationship between these features and pathologies (121, 132-136). A radiomics study of BPE DCE-MRI was able to differentiate subtypes of triple negative breast cancer (137). Another study combining BPE and $\mathrm{T}_{2}$-weighted breast MRI predicted NAC response with high accuracy (138). Texture parameters used as features in the support-vector machine learning approach show accurate prediction of benign and malignant breast lesions (133, 138-142). Texture parameters can consist of statistical and grey-level metrics in the sub- $1 \mathrm{~cm}$ region of interest in DCE images (139), the ADC map histogram combined with DCE-derived parametric maps $(140,141)$, and the parenchymal texture analysis (133). Finally, radiogenomics aims to identify imaging biomarkers and incorporates with phenotypic and genotypic metrics to support the execution of radiomics studies (142).

Machine learning has applications in breast lesion detection and classification, as well as predicting NAC response. Machine learning can bring together data from many studies and reduce the variability of radiologists' annotation methods on breast lesions. The current limitations of machine learning are the training requirement of large datasets and lack of standardized machine learning models to extract features from these datasets. Lastly, the decision-making process of machine learning can be considered a "black box"; it is difficult to intuitively explain how and why a certain answer is produced by machine learning models.

\section{Ultra-High Field MR Scanners 7 Tesla}

As indicated by the improved fat-water contrast visible in Figure 1, the positive predictive value and cancer detection rates of MRI increase at higher magnetic fields (143). However, the issue of transmit $B_{1}$ inhomogeneity is greater at ultrahigh fields, and it becomes necessary to utilize a local transmit coil for breast MRI at 7T (144). Given the proximity to the breasts and the greater net magnetization inherent at higher static magnetic fields, a local RF coil may be used for both transmit and receive (28). However, owing to the asymmetric dielectric load presented by the torso, transmit $\mathrm{B}_{1}$ inhomogeneity can still be pronounced throughout the breasts, leading to a linear signal drop-off toward the chest wall. In response, adiabatic pulse sequences have been developed to compensate for $\mathrm{B}_{1}$ inhomogeneity and improve tip angle uniformity (145). Alternatively, transmit coil designs exploiting transmission line techniques, e.g., forced current excitation (90, 146), have been shown to produce excellent $B_{1}$ homogeneity throughout the breast to the chest wall $\left[7.2 \% \mathrm{~B}_{1}\right.$ coefficient of variation reported in (147)] and facilitate the use of standardized pulse sequences. As with lower static fields, the received SNR is further improved by utilizing a 7T array coil insert (148-151).

\section{Ultra-High Field Safety}

The potential for RF power deposition to cause localized tissue heating is more apparent at higher fields. The amount of power dissipated in a given mass of tissue is quantified as specific absorption rate, and operational safety limits are stipulated by the International Electrotechnical Commission (152). The safety of local transmit coils must be validated, typically through thermometry measurements and electromagnetic simulation of the specific coil design. While higher specific absorption rate is expected for women with greater breast tissue density, their resulting levels for routine $7 \mathrm{~T}$ pulse sequences are generally well within safety limits $(153,154)$. Furthermore, a preliminary simulation study indicates the presence of breast implants has no significant effects on specific absorption rate or tissue heating (155).

\section{CONCLUSIONS AND FUTURE DIRECTIONS}

The current and emerging MRI techniques discussed in this paper are summarized in Table 1. For a multifaceted disease such as cancer, multi-parametric approach through which both structural and functional information can be elucidated simultaneously is a necessity to overcome the limitations of current MR based clinical modalities. In comparison to the stand-alone modalities, mpMRI enables both visualization and quantification. Quantifying varied cancer traits, including but not limited to, tumor architecture, tumor microenvironment, vascularization and angiogenesis, tumor heterogeneity, cellularity, metabolite concentration, and receptor status in parallel with image reconstruction through the combination of modalities would inevitably improve the status quo in detecting and treating breast cancer (156). Furthermore, individual modalities that appear far-removed from standalone efficacy may be ideal adjuncts for an mpMRI approach; for example, Weiss et al. recently demonstrated a promising approach to predict personalized response to NAC using a combination of DCE and DWI; however, the accuracy of their mathematical model would be strengthened by personalized measurements of elastic properties of the breast, potentially through MRE (157). Ultimately, mpMRI incorporating one or more emerging methods has the potential to afford improved specificity and deliver excellent 
TABLE 1 | Comparison of current and emerging MRI techniques.

\begin{tabular}{|c|c|c|c|c|c|}
\hline & \multicolumn{2}{|c|}{ Imaging techniques } & Clinical applications & Features and strengths & Limitations \\
\hline \multirow[t]{3}{*}{ Current MRI techniques } & \multicolumn{2}{|c|}{ Structural imaging } & $\begin{array}{l}T_{1} \text { and } T_{2} \text { weighted bilateral fat } \\
\text { suppression imaging }\end{array}$ & $\begin{array}{l}\text { Superior sensitivity for breast tumors; } \\
\text { preferable for dense breast imaging }\end{array}$ & $\begin{array}{l}\text { Low tumoral contrast, as tumor is } \\
\text { surrounded by breast fat and } \\
\text { fibroglandular tissue }\end{array}$ \\
\hline & \multirow[t]{2}{*}{$\begin{array}{l}\text { Contrast Enhanced } \\
\text { Perfusion MRI }\end{array}$} & \begin{tabular}{|l} 
Dynamic Contrast \\
Enhanced (DCE) MRI
\end{tabular} & $\begin{array}{l}\text { Routinely utilized for distinguishing } \\
\text { malignant vs benign cancers }\end{array}$ & $\begin{array}{l}\text { Microvasculature and hypersensitivity in } \\
\text { malignant tumors }\end{array}$ & Affected by hormones (menstrual cycle) \\
\hline & & $\begin{array}{l}\text { Background } \\
\text { Parenchymal } \\
\text { Enhancement (BPE) } \\
\text { MRI }\end{array}$ & $\begin{array}{l}\text { Breast cancer predicting odds for } \\
\text { patients at risk (32) }\end{array}$ & $\begin{array}{l}\text { Whole breast area enhancement; tissue } \\
\text { specific differences in normal tissues }\end{array}$ & $\begin{array}{l}\text { Recent studies fail to correlate positive } \\
\text { biopsy rate with specificity or sensitivity } \\
\text { (33) }\end{array}$ \\
\hline \multirow[t]{12}{*}{ Emerging MRI techniques } & \multirow[t]{2}{*}{$\begin{array}{l}\text { Diffusion Weighted MRI } \\
\text { (Gaussian) }\end{array}$} & $\begin{array}{l}\text { Diffusion Weighted } \\
\text { Imaging (DWI) }\end{array}$ & $\begin{array}{l}\text { Potential tissue cellularity-based } \\
\text { approach }\end{array}$ & $\begin{array}{l}\text { Improved lesion detection for } \\
\text { voxel-wise calculation ( } 47,48) \text {; higher } \\
\text { resolution achievable (e.g., } 0.8 \mathrm{~mm}) \\
\text { (47); yields superior quality when used } \\
\text { in combination with MRS or other } \\
\text { multiparametric modalities (46) }\end{array}$ & $\begin{array}{l}\text { Inconsistency in obtaining high-quality } \\
\text { breast DWI but can be solved with } \\
\text { protocol standardization and QA } \\
\text { procedure (see (49) for more details) }\end{array}$ \\
\hline & & $\begin{array}{l}\text { Diffusion Tensor } \\
\text { Imaging (DTI) }\end{array}$ & $\begin{array}{l}\text { Potentially differentiating breast cancer } \\
\text { subtypes }(54,55)\end{array}$ & $\begin{array}{l}\text { Distinction of malignant vs benign } \\
\text { lesions }\end{array}$ & $\begin{array}{l}\text { Reproducible results with higher } \\
\text { accuracy remain a challenge }\end{array}$ \\
\hline & \multirow[t]{2}{*}{$\begin{array}{l}\text { Diffusion Weighted MRI } \\
\text { (Non-Gaussian) }\end{array}$} & $\begin{array}{l}\text { Diffusion Kurtosis } \\
\text { Imaging }\end{array}$ & $\begin{array}{l}\text { Potential to differentiate heterogenous } \\
\text { tumor microstructures (62) }\end{array}$ & $\begin{array}{l}\text { Applicable for intracellular structures, } \\
\text { e.g., membranes and organelles (61); } \\
\text { improved unsuppressed fat signal (63) }\end{array}$ & $\begin{array}{l}\text { Low SNR; longer scanning time and } \\
\text { higher magnetic gradient strength for } \\
\text { high b-value acquisition }\end{array}$ \\
\hline & & $\begin{array}{l}\text { Intravoxel Incoherent } \\
\text { Motion }\end{array}$ & $\begin{array}{l}\text { Promising results in differentiating } \\
\text { malignant vs benign lesions; } \\
\text { neoadjuvant chemotherapy (NAC) } \\
\text { prediction }\end{array}$ & $\begin{array}{l}\text { Tissue diffusion and microcapillary } \\
\text { perfusion based; contrast Agents are } \\
\text { not required; }\end{array}$ & $\begin{array}{l}\text { Low SNR; longer scanning time and } \\
\text { higher magnetic gradient strength for } \\
\text { high b-value acquisition }\end{array}$ \\
\hline & \multirow[t]{3}{*}{$\begin{array}{l}\text { Magnetic Resonance } \\
\text { Spectroscopy (MRS) }\end{array}$} & & $\begin{array}{l}\text { Potential biomarker for malignant breast } \\
\text { cancer }\end{array}$ & $\begin{array}{l}\text { Highest sensitivity and simplest data } \\
\text { acquisition }\end{array}$ & $\begin{array}{l}\text { Issues related to reproducibility across } \\
\text { clinical sites (74) }\end{array}$ \\
\hline & & $\begin{array}{l}\text { Multinuclear } \\
\text { Spectroscopy }\end{array}$ & $\begin{array}{l}\text { Potential in identifying 'at risk' } \\
\text { population by monitoring } \\
\text { metabolism-based results }\end{array}$ & Tumor malignancy transformation study & Low SNR \\
\hline & & Magnetization Transfer & $\begin{array}{l}\text { Potential in monitoring response to } \\
\text { NAC; differentiating malignant tumors } \\
\text { vs benign lesions }\end{array}$ & $\begin{array}{l}\text { Facilitates detection of low } \\
\text { concentration chemicals }\end{array}$ & $\begin{array}{l}\text { Low SNR, benefits from higher } \\
\text { magnetic field strength }(7 T)\end{array}$ \\
\hline & \multirow[t]{5}{*}{ Other techniques } & Sodium MRI & $\begin{array}{l}\text { Potentially differentiating malignant } \\
\text { tumors based on sodium concentration } \\
\text { (101) }\end{array}$ & $\begin{array}{l}\text { No chemical or spectral shift observed; } \\
\text { based on sodium/potassium ion } \\
\text { channels in the body }\end{array}$ & $\begin{array}{l}\text { Could be overlapped with other } \\
\text { sodium/potassium ion channel related } \\
\text { disorder }\end{array}$ \\
\hline & & $\begin{array}{l}\text { Susceptibility- } \\
\text { Weighted } \\
\text { MRI }\end{array}$ & $\begin{array}{l}\text { Potential microcalcifications in breast } \\
\text { tissues (otherwise only visible using } \\
\text { mammography) }\end{array}$ & $\begin{array}{l}\text { Potential to determine ductal carcinoma } \\
\text { in situ that are often missed }\end{array}$ & $\begin{array}{l}\text { Possibility for MRI related artifacts in } \\
\text { images }\end{array}$ \\
\hline & & MR Elastography & $\begin{array}{l}\text { Applicable for differentiating malignant } \\
\text { vs benign lesions }\end{array}$ & $\begin{array}{l}\text { Characterization of biomechanical } \\
\text { tissue properties (microenvironmental } \\
\text { stiffness) }\end{array}$ & $\begin{array}{l}\text { Requires breast in contact with soft } \\
\text { sternal driver }\end{array}$ \\
\hline & & $\begin{array}{l}\text { Electrical Properties } \\
\text { Tomography }\end{array}$ & $\begin{array}{l}\text { Differentiate malignant vs benign } \\
\text { lesions; invasive ductal carcinoma vs } \\
\text { ductal carcinoma in situ (112) }\end{array}$ & $\begin{array}{l}\text { Utilizes undesirable distortions in } \\
\text { transmit field }\end{array}$ & Poor spatial resolution \\
\hline & & Machine Learning & $\begin{array}{l}\text { Lesion detection, lesion classification, } \\
\text { and predicting response after NAC }\end{array}$ & $\begin{array}{l}\text { Brings together data from a large } \\
\text { number of studies, and reduces } \\
\text { inter-reader variability caused by } \\
\text { readers' different annotations in breast } \\
\text { tumor masks }\end{array}$ & $\begin{array}{l}\text { Lack of standardization: no standard } \\
\text { method for segmentation and feature } \\
\text { extraction. Requires large datasets for } \\
\text { training. The decision-making process } \\
\text { is a 'black box,' hard to understand }\end{array}$ \\
\hline
\end{tabular}


accuracy for the prediction, detection, and monitoring of breast cancer (158).

Both DWI and ${ }^{1} \mathrm{H}$ MRS are considered important approaches to pursue the analysis of tumor growth and treatment response in vivo (159). Advanced DWI methods that have the potential to distinguish tumors, given distinct signatures of cellularity and intravoxel heterogeneity, hold great potential in the noninvasive differentiation of tumor subtypes. Specifically, the fractional order calculus model (160) can derive micrometerscale diffusion metrics that may reflect nuclear morphometry. To elicit sensitivity to shorter-scale diffusion, this method requires acquisitions with at least five $b$-values in the high range of $b=$ $3000-4000 \mathrm{~s} / \mathrm{mm}^{2}$. While one retrospective study failed to show improved utility of fractional order calculus model parameters as compared to DWI ADC, the maximum b-value acquisitions included in the study $\left(b=1500 \mathrm{~s} / \mathrm{mm}^{2}\right)$ were insufficient to properly evaluate the fractional order calculus model (161). Regarding ${ }^{1} \mathrm{H}$ MRS, current issues surrounding inter-site reproducibility of single-voxel MRS may be mitigated through automated voxel placement or full 3D magnetic resonance spectroscopic imaging (74), particularly if following standardized process for acquisition, post-processing, and analysis (162). Continued development of MT techniques, including amide proton transfer, also show promise for differentiating tumor subtypes and predicting treatment outcome. DWI, MRS, and amide proton transfer all will benefit from the growing footprint of 7T MR scanners and continued progress toward U.S. Food and Drug Administration approval of clinical breast cancer applications at $7 \mathrm{~T}$. Positron emission tomography (PET) as a stand-alone imaging technique is known to have a high diagnostic ability for metastasis through imaging of the breast and adjacent lymph nodes. The diagnosis and characterization of primary tumors using PET has been shown to be improved when used simultaneously in conjugation with MRI, owing to the strengths of the individual modalities (163), but more research on combined PET/MRI modality is required to provide enough

\section{REFERENCES}

1. American Cancer Society. Cancer Facts \& Figures. Available online at: https://www.cancer.org/content/dam/cancer-org/research/cancer-factsand-statistics/annual-cancer-facts-and-figures/2020/cancer-facts-andfigures-2020.pdf (accessed February 9, 2020).

2. Heller SL, Moy L. MRI breast screening revisited. J Magn Reson Imaging. (2019) 49:1212-21. doi: 10.1002/jmri.26547

3. Kuhl CK, Strobel K, Bieling H, Leutner C, Schild HH, Schrading S. Supplemental breast MR imaging screening of women with average risk of breast cancer. Radiology. (2017) 283:361-70. doi: 10.1148/radiol.2016161444

4. Shahid H, Wiedenhoefer JF, Dornbluth C, Otto P, Kist KA. An overview of breast MRI. J Appl Radiol. (2016) 45:7-13. Available online at: https:// appliedradiology.com/articles/an-overview-of-breast-mri

5. Kuhl CK, Mielcareck P, Klaschik S, Leutner C, Wardelmann E, Gieseke J, et al. Dynamic breast MR imaging: are signal intensity time course data useful for differential diagnosis of enhancing lesions? Radiology. (1999) 211:101-10. doi: 10.1148/radiology.211.1.r99ap38101

6. Orel SG. Differentiating benign from malignant enhancing lesions identified at MR imaging of the breast: are time-signal intensity curves an accurate predictor? Radiology. (1999) 211:5-7. doi: 10.1148/radiology.211.1.r99ap395 supportive evidence of their higher sensitivities. Radiation associated with the tracer in PET could be another concern; however, Melsaether et al. have demonstrated 50\% reduction in total radiation dose when switching from PET/computed tomography to PET/MRI in a population of breast cancer patients, implying a safer mode of imaging and diagnosis in comparison to the former (164).

Finally, the rapidly advancing field of machine learning will facilitate more impactful applications for breast cancer detection and management, likely improving specificity, positive predictive value, and differentiation of tumor subtypes through MRI. Moreover, simultaneous assessments of biomarkers and their genomics data through radiogenomics is likely to prove instrumental in the future as we advance toward precision health or personalized medicine and simultaneously decrease the MRI associated false positive rates.

\section{AUTHOR CONTRIBUTIONS}

$\mathrm{AC}, \mathrm{XL}$, and JR drafted the manuscript. XL generated new figures. All authors contributed to manuscript revision and approved the submitted version.

\section{FUNDING}

The authors acknowledge support from the Purdue University Center for Cancer Research (NIH grant P30CA023168) and the Showalter Trust. XL and JR are partially funded by NIH grants R03EB026231 and R01EB024408.

\section{ACKNOWLEDGMENTS}

The authors thank the Purdue Graduate School, the Interdisciplinary Biomedical Sciences (IBSC) program, and the Showalter Trust for bestowing graduate fellowship support to AC.

7. Kuhl CK, Keulers A, Strobel K, Schneider H, Gaisa N, Schrading S. Not all false positive diagnoses are equal: on the prognostic implications of false-positive diagnoses made in breast MRI versus in mammography/digital tomosynthesis screening. Breast Cancer Research. (2018) 20:13. doi: 10.1186/s13058-018-0937-7

8. National Breast Cancer Foundation. Male Breast Cancer. Available online at: https://www.nationalbreastcancer.org/male-breast-cancer (accessed February 9, 2020).

9. American Cancer Society. Breast Cancer in Men. Available online at: https:// www.cancer.org/cancer/breast-cancer-in-men.html (accessed February 9, 2020).

10. Shaw A, Smith B, Howlett D. Male breast carcinoma and the use of MRI. Radiology Case Reports. (2015) 6:455. doi: 10.2484/rcr.v6i3.455

11. Shin K, Martaindale S, Whitman GJ. Male breast magnetic resonance imaging: when is it helpful? our experience over the last decade. Curr Probl Diagn Radiol. (2019) 48:196-203. doi: 10.1067/j.cpradiol.2018. 01.002

12. Liu N, Johnson KJ, Ma CX. Male breast cancer: an updated surveillance, epidemiology, and end results data analysis. Clin Breast Cancer. (2018) 18:997-1002. doi: 10.1016/j.clbc.2018. 06.013 
13. Wang F, Shu X, Meszoely I, Pal T, Mayer IA, Yu Z, et al. Overall mortality after diagnosis of breast cancer in men vs women. JAMA Oncol. (2019) 5:1589-96. doi: 10.1001/jamaoncol.2019.2803

14. Food and Drug Administration. Male Breast Cancer: Developing Drugs for Treatment Draft - Guidance for Industry. Rockville, MD: U.S. Department of health and human services; (2019). Available online at: https://www.fda.gov/ media/130061/download (accessed February 9, 2020).

15. Silvestri V, Barrowdale D, Mulligan AM, Neuhausen SL, Fox S, Karlan BY, et al. Male breast cancer in BRCA1 and BRCA2 mutation carriers: pathology data from the Consortium of Investigators of Modifiers of BRCA1/2. Breast Cancer Res. (2016) 18:15. doi: 10.1186/s13058-016-0671-y

16. Huuse EM, Moestue SA, Lindholm EM, Bathen TF, Nalwoga H, Krüger $\mathrm{K}$, et al. In vivo MRI and histopathological assessment of tumor microenvironment in luminal-like and basal-like breast cancer xenografts. J Magn Reson Imaging. (2012) 35:1098-107. doi: 10.1002/jmri.23507

17. Ahmed Sultan A, Hanry Al-backry M, Mohamed Alhefney E, Ezat Mosa A, Abdullah Farahat HE. Role of MR spectroscopy and diffusion-weighted imaging in diagnosis of orbital masses. Egypt J Radiol Nucl Med. (2018) 49:45-53. doi: 10.1016/j.ejrnm.2017.11.005

18. Belli P, Costantini M, Bufi E, Giardina GG, Rinaldi P, Franceschini G, et al. Diffusion magnetic resonance imaging in breast cancer characterisation: correlations between the apparent diffusion coefficient and major prognostic factors. Radiol Med. (2015) 120:268-76. doi: 10.1007/s11547-014-0442-8

19. Li G, Chen R, Hao L, Lin L. Three dimensional MREIT for breast cancer detection on open MRI scanners. In: Proceedings of the 2012 IEEE International Conference on Information and Automation. Shenyang; New York, NY: IEEE (2012). p. 446-50. doi: 10.1109/ICInfA.2012.6246847

20. Partridge SC, McDonald ES. Diffusion weighted magnetic resonance imaging of the breast: protocol optimization, interpretation, and clinical applications. Magn Reson Imaging Clin N Am. (2013) 21:601-24. doi: 10.1016/j.mric.2013.04.007

21. Penet M-F, Mikhaylova M, Li C, Krishnamachary B, Glunde K, Pathak AP, et al. Applications of molecular MRI and optical imaging in cancer. Future Med Chem. (2010) 2:975-88. doi: 10.4155/fmc.10.25

22. Chu W, Jin W, Liu D, Wang J, Geng C, Chen L, et al. Diffusionweighted imaging in identifying breast cancer pathological response to neoadjuvant chemotherapy: a meta-analysis. Oncotarget. (2018) 9:7088100. doi: 10.18632/oncotarget.23195

23. Checka CM, Chun JE, Schnabel FR, Lee J, Toth H. The relationship of mammographic density and age: implications for breast cancer screening. Am J Roentgenol. (2012) 198:292-509. doi: 10.2214/AJR.10.6049

24. Sardanelli F, Giusepprtti GM, Panizza P, Bazzocchi M, Fausto A, Simonetti G, et al. Sensitivity of MRI versus mammography for detecting foci of multifocal, multicentric breast cancer in fatty and dense breasts using the whole-Breast pathologic examination as a gold standard. Am J Roentgenol. (2004) 183:1149-57. doi: 10.2214/ajr.183.4.1831149

25. Morris E, Comstock C, Lee C. ACR BI-RADS ${ }^{\circledR}$ Magnetic Resonance Imaging. ACR BI-RADS ${ }^{\circledR}$ Atlas, Breast Imaging Reporting and Data System. Reston, VA: American College of Radiology. (2013) doi: 10.1016/j.mric.2013.04.006

26. Boyd NF, Guo H, Martin LJ, Sun L, Stone J, Fishell E, et al. Mammographic density and the risk and detection of breast cancer. N Engl J Med. (2007) 356:227-36. doi: 10.1056/NEJMoa062790

27. Medved M, Li H, Abe H, Sheth D, Newstead GM, Olopade OI, et al. Fast bilateral breast coverage with high spectral and spatial resolution (HiSS) MRI at 3T. J Magn Reson Imaging. (2017) 46:1341-8. doi: 10.1002/jmri.25658

28. Brown R, Storey P, Geppert C, McGorty K, Klautau Leite AP, Babb J, et al. Breast MRI at 7 tesla with a bilateral coil and robust fat suppression. J Magn Reson Imaging. (2014) 39:540-9. doi: 10.1002/jmri.24205

29. Delille J-P, Slanetz PJ, Yeh ED, Kopans DB, Garrido L. Physiologic changes in breast magnetic resonance imaging during the menstrual cycle: perfusion imaging, signal enhancement, and influence of the $\mathrm{T}_{1}$ relaxation time of breast tissue. Breast J. (2005) 11:236-41. doi: 10.1111/j.1075-122X.2005.21499.x

30. Kuhl CK, Bieling HB, Gieseke J, Kreft BP, Sommer T, Lutterbey $\mathrm{G}$, et al. Healthy premenopausal breast parenchyma in dynamic contrast-enhanced MR imaging of the breast: normal contrast medium enhancement and cyclical-phase dependency. Radiology. (1997) 203:137-44. doi: 10.1148/radiology.203.1.9122382
31. Newitt D, Hylton N. Data from: Multi-center breast DCE-MRI data and segmentations from patients in the I-SPY 1/ACRIN 6657 trials. Cancer Imag Arch. (2016) 198:W373-80. doi: 10.7937/K9/TCIA.2016.Hd HpgJLK

32. King V, Brooks JD, Bernstein JL, Reiner AS, Pike MC, Morris EA. Background parenchymal enhancement at breast MR imaging and breast cancer risk. Radiology. (2011) 260:50-60. doi: 10.1148/radiol.11102156

33. DeMartini WB, Liu F, Peacock S, Eby PR, Gutierrez RL, Lehman CD. Background parenchymal enhancement on breast MRI: impact on diagnostic performance. Am J Roentgenol. (2012) 198:W373-W80. doi: 10.2214/AJR.10.6272

34. Kuhl CK, Kooijman H, Gieseke J, Schild HH. Effect of $B_{1}$ inhomogeneity on breast $\mathrm{mr}$ imaging at 3.0 T. Radiology. (2007) 244:929-30. doi: 10.1148/radiol.2443070266

35. Azlan CA, Di Giovanni P, Ahearn TS, Semple SIK, Gilbert FJ, Redpath TW. $B_{1}$ transmission-field inhomogeneity and enhancement ratio errors in dynamic contrast-enhanced MRI (DCE-MRI) of the breast at 3T. J Magn Reson Imaging. (2010) 31:234-9. doi: 10.1002/jmri.22018

36. Sung K, Daniel BL, Hargreaves BA. Transmit $\mathrm{B}_{1}^{+}$field inhomogeneity and $\mathrm{T}_{1}$ estimation errors in breast DCE-MRI at 3 tesla. J Magn Reson Imaging. (2013) 38:454-9. doi: 10.1002/jmri.23996

37. Azlan CA, Ahearn TS, Di Giovanni P, Semple SIK, Gilbert FJ, Redpath TW. Quantification techniques to minimize the effects of native $T_{1}$ variation and $B_{1}$ inhomogeneity in dynamic contrast enhanced MRI of the breast at $3 \mathrm{~T}$. Magn Reson Med. (2012) 67:531-40. doi: 10.1002/mrm.23021

38. Wright SM, Wald LL. Theory and application of array coils in MR spectroscopy. NMR in Biomedicine. (1997) 10:394-410. doi: 10.1002/ (SICI)1099-1492(199712)10:8<394::AID-NBM494>3.0.CO;2-0

39. Konyer NB, Ramsay EA, Bronskill MJ, Plewes DB. Comparison of MR imaging breast coils. Radiology. (2002) 222:8304. doi: 10.1148/radiol.2223001310

40. Marshall H, Devine PM, Shanmugaratnam N, Fobel R, Siegler P, Piron CA, et al. Evaluation of multicoil breast arrays for parallel imaging. J Magn Reson Imaging. (2010) 31:328-38. doi: 10.1002/jmri.22023

41. Nnewihe AN, Grafendorfer T, Daniel BL, Calderon P, Alley MT, Robb F, et al. Custom-fitted 16-channel bilateral breast coil for bidirectional parallel imaging. Magn Reson Med. (2011) 66:281-9. doi: 10.1002/mrm.22771

42. Hancu I, Fiveland E, Park K, Giaquinto RO, Rohling K, Wiesinger F. Flexible, 31-channel breast coil for enhanced parallel imaging performance at 3T. Magn Reson Med. (2016) 75:897-905. doi: 10.1002/mrm.25655

43. Li T, Yu T, Li L, Lu L, Zhuo Y, Lian J, et al. Use of diffusion kurtosis imaging and quantitative dynamic contrast-enhanced MRI for the differentiation of breast tumors. J Magn Reson Imaging. (2018) 48:1358-66. doi: 10.1002/jmri.26059

44. Zhou J, Chen E, Xu H, Ye Q, Li J, Ye S, et al. Feasibility and diagnostic performance of voxelwise computed diffusion-weighted imaging in breast cancer. J Magn Reson Imaging. (2018) 49:1610-6. doi: 10.1002/jmri. 26533

45. Solomon E, Nissan N, Furman-Haran E, Seginer A, Shapiro-Feinberg M, Degani $\mathrm{H}$, et al. Overcoming limitations in diffusion-weighted MRI of breast by spatio-temporal encoding. Magn Reson Med. (2015) 73:216373. doi: $10.1002 / \mathrm{mrm} .25344$

46. Pinker K, Moy L, Sutton EJ, Mann RM, Weber M, Thakur SB, et al. DiffusionWeighted imaging with apparent diffusion coefficient mapping for breast cancer detection as a stand-alone parameter: comparison with dynamic contrast-enhanced and multiparametric magnetic resonance imaging. Invest Radiol. (2018) 53:587-95. doi: 10.1097/RLI.0000000000000465

47. Barentsz MW, Taviani V, Chang JM, Ikeda DM, Miyake KK, Banerjee S, et al. Assessment of tumor morphology on diffusion-weighted (DWI) breast MRI: diagnostic value of reduced field of view DWI. J Magn Reson Imaging. (2015) 42:1656-65. doi: 10.1002/jmri.24929

48. Taviani V, Alley MT, Banerjee S, Nishimura DG, Daniel BL, Vasanawala SS, et al. High-resolution diffusion-weighted imaging of the breast with multiband $2 \mathrm{D}$ radiofrequency pulses and a generalized parallel imaging reconstruction. Magn Reson Med. (2016) 77:209-20. doi: 10.1002/mrm.26110

49. Newitt DC, Zhang Z, Gibbs JE, Partridge SC, Chenevert TL, Rosen MA, et al. Test-retest repeatability and reproducibility of ADC measures by breast 
DWI: results from the ACRIN 6698 trial. J Magn Reson Imaging. (2019) 49:1617-28. doi: 10.1002/jmri.26539

50. Partridge SC, Nissan N, Rahbar H, Kitsch AE, Sigmund EE. Diffusionweighted breast MRI: clinical applications and emerging techniques. J Magn Reson Imaging. (2017) 45:337-55. doi: 10.1002/jmri.25479

51. Eyal E, Shapiro-Feinberg M, Furman-Haran E, Grobgeld D, Golan T, Itzchak Y, et al. Parametric diffusion tensor imaging of the breast. Invest Radiol. (2012) 47:284-91. doi: 10.1097/RLI.0b013e3182438e5d

52. Furman-Haran E, Grobgeld D, Nissan N, Shapiro-Feinberg M, Degani H. Can diffusion tensor anisotropy indices assist in breast cancer detection? J Magn Reson Imaging. (2016) 44:1624-32. doi: 10.1002/jmri.25292

53. Ye Z, Zhao N, Lin J, Gary SE, Viox JD, Song C, et al. Quantification of benign and malignant breast tumor cellularity. In: Proceedings of the ISMRM 27th Annual Meeting \& Exhibition 2019. Montréal, QC; Concord, CA: ISMRM (2019). p. 277. Available online at: https://index.mirasmart. com/ISMRM2019/PDFfiles/0277.html (accessed February 9, 2020).

54. Onaygil C, Kaya H, Ugurlu MU, Aribal E. Diagnostic performance of diffusion tensor imaging parameters in breast cancer and correlation with the prognostic factors. J Magn Reson Imaging. (2017) 45:66072. doi: 10.1002/jmri.25481

55. Ozal ST, Inci E, Gemici AA, Turgut H, Cikot M, Karabulut M. Can 3.0 tesla diffusion tensor imaging parameters be prognostic indicators in breast cancer? Clin Imaging. (2018) 51:240-7. doi: 10.1016/j.clinimag.2018.03.022

56. Partridge SC, Murthy RS, Ziadloo A, White SW, Allison KH, Lehman CD. Diffusion tensor magnetic resonance imaging of the normal breast. Magn Reson Imaging. (2010) 28:320-8. doi: 10.1016/j.mri.2009.10.003

57. Tagliafico A, Rescinito G, Monetti F, Villa A, Chiesa F, Fisci E, et al. Diffusion tensor magnetic resonance imaging of the normal breast: reproducibility of DTI-derived fractional anisotropy and apparent diffusion coefficient at $3.0 \mathrm{~T}$. Radiol Med. (2012) 117:992-1003. doi: 10.1007/s11547-012-0831-9

58. Wang Y, Zhang X-P, Li Y-L, Li X-T, Hu Y, Cui Y, et al. Optimization of the parameters for diffusion tensor magnetic resonance imaging data acquisition for breast fiber tractography at 1.5 T. Clin Breast Cancer. (2014) 14:61-7. doi: 10.1016/j.clbc.2013.09.002

59. Nissan N, Furman-Haran E, Feinberg-Shapiro M, Grobgeld D, Eyal E, Zehavi $\mathrm{T}$, et al. Tracking the mammary architectural features and detecting breast cancer with magnetic resonance diffusion tensor imaging. J Vis Exp. (2014) 94:e52048. doi: 10.3791/52048

60. Reisert M, Weigel M, Eyal E, Grobgeld D, Degani H, Hennig J. Diffusion tensor-based reconstruction of the ductal tree. In: Proceedings of the ISMRM 19th Annual Meeting \& Exhibition 2011. Montréal, QC; Concord, CA: ISMRM (2011). p. 1011. Available online at: https://cds.ismrm.org/ protected/11MProceedings/files/1011.pdf (accessed February 9, 2020).

61. Jensen JH, Helpern JA. MRI quantification of non-Gaussian water diffusion by kurtosis analysis. NMR Biomed. (2010) 23:698-710. doi: 10.1002/nbm.1518

62. Tang L, Zhou XJ. Diffusion MRI of cancer: from low to high b-values. J Magn Reson Imaging. (2019) 49:23-40. doi: 10.1002/jmri.26293

63. Mlynarska-Bujny A, Bickelhaupt S, König F, Laun F, Lederer W, Daniel $\mathrm{H}$, et al. Einflussvon nicht vollständig unterdrücktem Fettsignal auf die Diffusions-Kurtosis-Bildgebung in der MRI-Mammografie [Influence of incompletely suppressed fat signal on diffusion kurtosis imaging in MR mammography]. Fortschr Röntgenstr. (2019) 191:308. doi: 10.1055/s-0037-1682122

64. Bihan DL, Breton E, Lallemand D, Grenier P, Cabanis E, LavalJeantet M. MR imaging of intravoxel incoherent motions: application to diffusion and perfusion in neurologic disorders. Radiology. (1986) 161:401407. doi: 10.1148/radiology.161.2.3763909

65. Iima M. Investigation of new cancer diagnosis using nonGaussian diffusion MRI and IVIM. Impact. (2018) 2018:413. doi: $10.21820 / 23987073.2018 .12 .41$

66. Iima M, Kataoka M. IVIM MRI of the Breast. In: Bihan DL, Iima M, Federau C, Sigmund EE, editors. Intravoxel Incoherent Motion (IVIM) MRI: Principles and Applications. New York, NY: Jenny Stanford (2018). p. 17394. doi: 10.1201/9780429427275-8

67. Dijkstra H, Dorrius MD, Wielema M, Jaspers K, Pijnappel RM, Oudkerk $\mathrm{M}$, et al. Semi-automated quantitative intravoxel incoherent motion analysis and its implementation in breast diffusion-weighted imaging. J Magn Reson Imaging. (2016) 43:1122-31. doi: 10.1002/jmri.25086

68. Liu C, Liang C, Liu Z, Zhang S, Huang B. Intravoxel incoherent motion (IVIM) in evaluation of breast lesions: comparison with conventional DWI. Eur J Radiol. (2013) 82:e782-e9. doi: 10.1016/j.ejrad.2013.08.006

69. Cho GY, Gennaro L, Sutton EJ, Zabor EC, Zhang Z, Giri D, et al. Intravoxel incoherent motion (IVIM) histogram biomarkers for prediction of neoadjuvant treatment response in breast cancer patients. Eur J Radiol Open. (2017) 4:101-7. doi: 10.1016/j.ejro.2017.07.002

70. Tkáć I, Öz G, Adriany G, Ugurbil K, Gruetter R. In vivo ${ }^{1} \mathrm{H}$ NMR spectroscopy of the human brain at high magnetic fields: metabolite quantification at $4 \mathrm{~T}$ vs 7T. Magn Reson Med. (2009) 62:868-79. doi: $10.1002 / \mathrm{mrm} .22086$

71. Bolan PJ, Nelson MT, Yee D, Garwood M. Imaging in breast cancer: magnetic resonance spectroscopy. Breast Cancer Res. (2005) 7:149. doi: $10.1186 / \mathrm{bcr} 1202$

72. Baltzer PAT, Dietzel M. Breast lesions: diagnosis by using proton MR spectroscopy at 1.5 and $3.0 \mathrm{~T}$-systematic review and meta-analysis. Radiology. (2013) 267:735-746. doi: 10.1148/radiol.13121856

73. Rosi A, Grande S, Luciani AM, Palma A, Giovannini C, Guidoni L, et al. Role of glutathione in apoptosis induced by radiation as determined by ${ }^{1} \mathrm{H}$ MR spectra of cultured tumor cells. Radiat Res. (2007) 167:26882 doi: 10.1667/RR0578.1

74. Bolan PJ, Kim E, Herman BA, Newstead GM, Rosen MA, Schnall MD et al. MR spectroscopy of breast cancer for assessing early treatment response: results from the ACRIN 6657 MRS trial. J Magn Reson Imaging. (2017) 46:290-302. doi: 10.1002/jmri.25560

75. Glunde K, Penet M-F, Jiang L, Jacobs MA, Bhujwalla ZM. Choline metabolism-based molecular diagnosis of cancer: an update. Expert Rev Mol Diagn. (2015) 15:735-47. doi: 10.1586/14737159.2015.1039515

76. Sah RG, Agarwal K, Sharma U, Parshad R, Seenu V, Jagannathan NR. Characterization of malignant breast tissue of breast cancer patients and the normal breast tissue of healthy lactating women volunteers using diffusion MRI and in vivo ${ }^{1} \mathrm{H}$ MR spectroscopy. J Magn Reson Imaging. (2015) 41:169-74. doi: 10.1002/jmri.24507

77. Coum A, Ouldamer L, Noury F, Barantin L, Saint-Hilaire A, Vilde A. In vivo MR spectroscopy of human breast tissue: quantification of fatty acid composition at a clinical field strength (3 T). MAGMA. (2016) 29:14. doi: 10.1007/s10334-015-0506-3

78. Dimitrov IE, Douglas D, Ren J, Smith NB, Webb AG, Sherry AD, et al. In vivo determination of human breast fat composition by ${ }^{1} \mathrm{H}$ magnetic resonance spectroscopy at 7T. Magn Reson Med. (2012) 67:206. doi: $10.1002 / \mathrm{mrm} .22993$

79. Monaco ME. Fatty acid metabolism in breast cancer subtypes. Oncotarget. (2017) 8:29487-500. doi: 10.18632/oncotarget.15494

80. de Graaf RA, Klomp DWJ, Luijten PR, Boer VO. Intramolecular zeroquantum-coherence 2D NMR spectroscopy of lipids in the human breast at 7T. Magn Reson Med. (2014) 71:451-7. doi: 10.1002/mrm. 24701

81. Jagannathan NR. Application of in vivo MR methods in the study of breast cancer metabolism. NMR Biomed. (2019) 32:e4032. doi: 10.1002/ nbm. 4032

82. Esmaeili M, Moestue SA, Hamans BC, Veltien A, Kristian A, Engebråten $\mathrm{O}$, et al. In vivo ${ }^{31} \mathrm{P}$ magnetic resonance spectroscopic imaging (MRSI) for metabolic profiling of human breast cancer xenografts. J Magn Reson Imaging. (2015) 41:601-609. doi: 10.1002/jmri.24588

83. Schmitz AMT, Veldhuis WB, Menke-Pluijmers MBE, van der Kemp WJM, van der Velden TA, Viergever MA, et al. Preoperative indication for systemic therapy extended to patients with early-stage breast cancer using multiparametric 7-tesla breast MRI. PLoS One. (2017) 12:e0183855. doi: 10.1371/journal.pone. 0183855

84. van der Kemp WJM, Wijnen JP, Luijten PR, Klomp DWJ. Saturationtransfer effects and longitudinal relaxation times of ${ }^{31} \mathrm{P}$ metabolites in fibroglandular breast tissue at 7T. Magn Reson Med. (2015) 76:402407. doi: $10.1002 / \mathrm{mrm} .25871$

85. van der Kemp WJM, van der Velden TA, Schmitz AM, Gilhuijs KG, Luijten PR, Klomp DWJ, et al. Shortening of apparent transverse relaxation time 
of inorganic phosphate as a breast cancer biomarker. NMR Biomed. (2018) 32:e4011. doi: 10.1002/nbm.4011

86. Aboagye EO, Bhujwalla ZM. Malignant transformation alters membrane choline phospholipid metabolism of human mammary epithelial cells. Cancer Res. (1999) 59:80-84.

87. Franks SE, Kuesel AC, Lutz NW, Hull WE. ${ }^{31} \mathrm{P}$ MRS of human tumor cells: effects of culture media and conditions on phospholipid metabolite concentrations. Anticancer Res. (1996) 16:1365-74.

88. Krikken E, van der Kemp WJM, van Diest PJ, van Dalen T, van Laarhoven HWM, Luijten PR, et al. Early detection of changes in phospholipid metabolism during neoadjuvant chemotherapy in breast cancer patients using phosphorus magnetic resonance spectroscopy at 7T. NMR Biomed. (2019) 32:e4086. doi: 10.1002/nbm.4086

89. Shaka A, Keeler J, Frenkiel T, Freeman R. An improved sequence for broadband decoupling: WALTZ-16. J Magn Reson. (1983) 52:3358. doi: 10.1016/0022-2364(83)90207-X

90. McDougall MP, Cheshkov S, Rispoli J, Malloy C, Dimitrov I, Wright SM. Quadrature transmit coil for breast imaging at 7 tesla using forced current excitation for improved homogeneity. J Magn Reson Imaging. (2014) 40:1165-73. doi: 10.1002/jmri.24473

91. Glunde K, Jie C, Bhujwalla ZM. Molecular causes of the aberrant choline phospholipid metabolism in breast cancer. Cancer Res. (2004) 64:42706. doi: 10.1158/0008-5472.CAN-03-3829

92. Cheshkov S, Dimitrov IE, Rispoli J, Cui J, McDougall M, Wright S, et al. Protocol for investigating in vivo glucose metabolism in human breast cancer by ${ }^{13} \mathrm{C}$ MRS at 7T. In: Proceedings of the 25th Annual Meeting of ISMRM. Honolulu (2017). p. 2946.

93. Wolff SD, Balaban RS. Magnetization transfer contrast (MTC) and tissue water proton relaxation in vivo. Magn Reson Med. (1989) 10:13544. doi: 10.1002/mrm.1910100113

94. Arlinghaus LR, Dortch RD, Whisenant JG, Kang H, Abramson RG, Yankeelov TE. Quantitative magnetization transfer imaging of the breast at 3.0 T: reproducibility in healthy volunteers. Tomography. (2016) 2:2606. doi: 10.18383/j.tom.2016.00142

95. Dula AN, Arlinghaus LR, Dortch RD, Dewey BE, Whisenant JG, Ayers $\mathrm{GD}$, et al. Amide proton transfer imaging of the breast at $3 \mathrm{~T}$ : establishing reproducibility and possible feasibility assessing chemotherapy response. Magn Reson Med. (2013) 70:216-24. doi: 10.1002/mrm.24450

96. Virostko J, Sorace AG, Wu C, Ekrut D, Jarrett AM, Upadhyaya RM, et al. Magnetization transfer MRI of breast cancer in the community setting: reproducibility and preliminary results in neoadjuvant therapy. Tomography. (2019) 5:44-52. doi: 10.18383/j.tom.2018.00019

97. Chan KWY, Jiang L, Cheng M, Wijnen JP, Liu G, Huang P, et al. CEST-MRI detects metabolite levels altered by breast cancer cell aggressiveness and chemotherapy response. NMR Biomed. (2016) 29:806-16. doi: 10.1002/nbm.3526

98. Krikken E, Khlebnikov V, Zaiss M, Jibodh RA, van Diest PJ, Luijten PR, et al. Amide chemical exchange saturation transfer at $7 \mathrm{~T}$ : a possible biomarker for detecting early response to neoadjuvant chemotherapy in breast cancer patients. Breast Cancer Res. (2018) 20:51. doi: 10.1186/s13058-018-0982-2

99. Donahue MJ, Donahue PCM, Rane S, Thompson CR, Strother MK, Scott AO, et al. Assessment of lymphatic impairment and interstitial protein accumulation in patients with breast cancer treatment-related lymphedema using CEST MRI. Magn Reson Med. (2016) 75:34555. doi: 10.1002/mrm.25649

100. Klomp DWJ, Dula AN, Arlinghaus LR, Italiaander M, Dortch RD, Zu Z, et al. Amide proton transfer imaging of the human breast at 7T: development and reproducibility. NMR Biomed. (2013) 26:1271-7. doi: 10.1002/ nbm.2947

101. Kaggie JD, Hadley JR, Badal J, Park DJ, Parker DL, Morrell G, et al. A 3 T sodium and proton composite array breast coil. Magn Reson Med. (2014) 71:2231-42. doi: 10.1002/mrm.24860

102. Ouwerkerk R, Jacobs MA, Macura KJ, Wolff AC, Stearns V, Mezban SD, et al. Elevated tissue sodium concentration in malignant breast lesions detected with non-invasive ${ }^{23} \mathrm{Na}$ MRI. Breast Cancer Res Treat. (2007) 106:151-60. doi: 10.1007/s10549-006-9485-4

103. Zaric O, Pinker K, Zbyn S, Strasser B, Robinson S, Minarikova L, et al. Quantitative sodium mr imaging at $7 \mathrm{~T}$ : initial results and comparison with diffusion-weighted imaging in patients with breast tumors. Radiology. (2016) 280:39-48. doi: 10.1148/radiol.2016151304

104. Gilles R, Zafrani B, Guinebretière JM, Meunier M, Lucidarme O, Tardivon AA, et al. Ductal carcinoma in situ: MR imaging-histopathologic correlation. Radiology. (1995) 196:415-9. doi: 10.1148/radiology.196.2.76 17854

105. Cheshkov S, Gilbert G, Dimitrov I, By S, Rispoli J, McDougall M, et al. In-vivo breast microcalcification detection via susceptibility weighted imaging at $7 \mathrm{~T}$. In: Proceedings of the ISMRM 22nd Annual Meeting \& Exhibition 2014. Milan; Concord, CA: ISMRM (2014). p. 3282. Available online at: https:// cds.ismrm.org/protected/14MProceedings/files/3282.pdf (accessed February 9, 2020).

106. Sinkus R, Siegmann K, Xydeas T, Tanter M, Claussen C, Fink M. MR elastography of breast lesions: understanding the solid/liquid duality can improve the specificity of contrast-enhanced MR mammography. Magn Reson Med. (2007) 58:1135-44. doi: 10.1002/mrm.21404

107. Bohte AE, Nelissen JL, Runge JH, Holub O, Lambert SA, de Graaf L, et al. Breast magnetic resonance elastography: a review of clinical work and future perspectives. NMR Biomed. (2018) 31:e3932. doi: 10.1002/nbm.3932

108. Ma D, Gulani V, Seiberlich N, Liu K, Sunshine JL, Duerk $\mathrm{JL}$, et al. Magnetic resonance fingerprinting. Nature. (2013) 495:187-92. doi: 10.1038/nature11971

109. Chen Y, Panda A, Pahwa S, Hamilton JI, Dastmalchian S, McGivney DF. Three-dimensional MR fingerprinting for quantitative breast imaging. Radiology. (2019) 290:33-40 doi: 10.1148/radiol.2018180836

110. Panda A, Chen Y, Ropella-Panagis K, Ghodasara S, Stopchinski M, Seyfried N., et al. Repeatability and reproducibility of 3D MR fingerprinting relaxometry measurements in normal breast tissue. J Magn Reson Imaging. (2019) 50:1133-43. doi: 10.1002/jmri.26717

111. Katscher U, Berg CAT. Electric properties tomography: biochemical, physical and technical background, evaluation and clinical applications. NMR Biomed. (2017) 30:e3729. doi: 10.1002/nbm.3729

112. Shin J, Kim MJ, Lee J, Nam Y, M-o K, Choi N, et al. Initial study on in vivo conductivity mapping of breast cancer using MRI. J Magn Reson Imaging. (2015) 42:371-8. doi: 10.1002/jmri.24803

113. Cavallo Marincola B, Telesca M, Zaccagna F, Reimer F, Anzidei M, Catalano $\mathrm{C}$, et al. Can unenhanced MRI of the breast replace contrast-enhanced MRI in assessing response to neoadjuvant chemotherapy? Acta Radiol. (2019) 60:35-44. doi: 10.1177/0284185118773512

114. Alhamami M, Cheng W, Lyu Y, Allen C, Zhang X-A, Cheng H-LM. Manganese-porphyrin-enhanced MRI for the detection of cancer cells: a quantitative in vitro investigation with multiple clinical subtypes of breast cancer. PLoS ONE. (2018) 13:e0206720. doi: 10.1371/journal.pone. 0206720

115. Ganesh T, Mokhtari RB, Alhamami M, Yeger H, Cheng H-LM. Manganeseenhanced MRI of minimally gadolinium-enhancing breast tumors. J Magn Reson Imaging. (2015) 41:806-813. doi: 10.1002/jmri.24608

116. Boehm-Sturm P, Haeckel A, Hauptmann R, Mueller S, Kuhl CK, Schellenberger EA. Low-molecular-weight iron chelates may be an alternative to gadolinium-based contrast agents for $\mathrm{T}_{1}$-weighted contrast-enhanced $\mathrm{MR}$ imaging. Radiology. (2018) 286:537-46. doi: 10.1148/radiol.2017170116

117. Zhou Z, Qutaish M, Han Z, Schur RM, Liu Y, Wilson DL, et al. MRI detection of breast cancer micrometastases with a fibronectin-targeting contrast agent. Nat Commun. (2015) 6:7984. doi: 10.1038/ncomms8984

118. Allen B. How structured use cases can drive the adoption of artificial intelligence tools in clinical practice. J Am Coll Radiol. (2018) 15:175860. doi: 10.1016/j.jacr.2018.09.002

119. Sprague BL, Conant EF, Onega T, Garcia MP, Beaber EF, Herschorn SD, et al. Variation in mammographic breast density assessments among radiologists in clinical practice: a multicenter observational study. Ann Intern Med. (2016) 165:457-64. doi: 10.7326/M15-2934

120. Reig B, Heacock L, Geras KJ, Moy L. Machine learning in breast MRI. J Magn Reson Imaging. (2020) 55:57-68. doi: 10.1002/jmri.26852

121. Machireddy A, Thibault G, Tudorica A, Afzal A, Mishal M, Kemmer K, et al. Early prediction of breast cancer therapy response using multiresolution fractal analysis of DCE-MRI parametric maps. Tomography. (2019) 5:908. doi: 10.18383/j.tom.2018.00046 
122. Zhou J, Luo L-Y, Dou Q, Chen H, Chen C, Li G-J, et al. Weakly supervised 3D deep learning for breast cancer classification and localization of the lesions in MR images. J Magn Reson Imaging. (2019) 50:114451. doi: 10.1002/jmri.26721

123. Ertas G, Doran SJ, Leach MO. A computerized volumetric segmentation method applicable to multi-centre MRI data to support computer-aided breast tissue analysis, density assessment and lesion localization. Med Biol Eng Comput. (2016) 55:57-68. doi: 10.1007/s11517-016-1484-y

124. Wu S, Weinstein SP, Conant EF, Kontos D. Automated fibroglandular tissue segmentation and volumetric density estimation in breast MRI using an atlas-aided fuzzy C-means method. Med Phys. (2013) 40:112302. doi: 10.1118/1.4829496

125. Wu S, Zuley ML, Berg WA, Kurland BF, Jankowitz RC, Sumkin JH, et al. DCE-MRI background parenchymal enhancement quantified from an early versus delayed post-contrast sequence: association with breast cancer presence. Sci Rep. (2017) 7:2115. doi: 10.1038/s41598-017-02341-8

126. Jafri NF, Newitt DC, Kornak J, Esserman LJ, Joe BN, Hylton NM. Optimized breast MRI functional tumor volume as a biomarker of recurrence-free survival following neoadjuvant chemotherapy. J Magn Reson Imaging. (2013) 40:476-82. doi: 10.1002/jmri.24351

127. Mustra M, Grgic M, Rangayyan RM. Review of recent advances in segmentation of the breast boundary and the pectoral muscle in mammograms. Med Biol Eng Comput. (2016) 54:1003-24. doi: 10.1007/s11517-015-1411-7

128. Klifa C, Carballido-Gamio J, Wilmes L, Laprie A, Lobo C, DeMicco E. Quantification of breast tissue index from MR data using fuzzy clustering. In: Proceedings of the 26th Annual International Conference of the IEEE Engineering in Medicine Biology Society 2004. San Francisco, CA; New york, NY: IEEE (2004). p.1667-70.

129. Fashandi H, Kuling G, Lu Y, Wu H, Martel AL. An investigation of the effect of fat suppression and dimensionality on the accuracy of breast MRI segmentation using U-nets. Med Phys. (2019) 46:123044. doi: $10.1002 / \mathrm{mp} .13375$

130. Zhang Y, Chen J-H, Chang K-T, Park VY, Kim MJ, Chan S, et al. Automatic breast and fibroglandular tissue segmentation in breast MRI using deep learning by a fully-convolutional residual neural network U-net. Acad Radiol. (2019) 26:1526-35 doi: 10.1016/j.acra.2019.01.012

131. Dalmiş MU, Litjens G, Holland K, Setio A, Mann R, Karssemeijer N, et al. Using deep learning to segment breast and fibroglandular tissue in MRI volumes. Med Phys. (2017) 44:533-46. doi: 10.1002/mp.12079

132. Chitalia RD, Kontos D. Role of texture analysis in breast MRI as a cancer biomarker: a review. J Magn Reson Imaging. (2018) 49:92738. doi: 10.1002/jmri.26556

133. Gastounioti A, Conant EF, Kontos D. Beyond breast density: a review on the advancing role of parenchymal texture analysis in breast cancer risk assessment. Breast Cancer Res. (2016) 18:91. doi: 10.1186/s13058-016-0755-8

134. Li H, Zhu Y, Burnside ES, Huang E, Drukker K, Hoadley KA, et al. Quantitative MRI radiomics in the prediction of molecular classifications of breast cancer subtypes in the TCGA/TCIA data set. npj Breast Cancer. (2016) 2:16012. doi: $10.1038 /$ npjbcancer.2016.12

135. Bickelhaupt S, Jaeger PF, Laun FB, Lederer W, Daniel H, Kuder TA, et al. Radiomics based on adapted diffusion kurtosis imaging helps to clarify most mammographic findings suspicious for cancer. Radiology. (2018) 287:76170. doi: 10.1148/radiol.2017170273

136. Liu Z, Li Z, Qu J, Zhang R, Zhou X, Li L, et al. Radiomics of multi-parametric MRI for pretreatment prediction of pathological complete response to neoadjuvant chemotherapy in breast cancer: a multicenter study. Clin Cancer Res. (2019) 50:1468-77. doi: 10.1158/1078-0432.CCR-18-3190

137. Wang J, Kato F, Oyama-Manabe N, Li R, Cui Y, Tha KK, et al. Identifying triple-negative breast cancer using background parenchymal enhancement heterogeneity on dynamic contrast-enhanced MRI: a pilot radiomics study. PLoS ONE. (2015) 10:e0143308. doi: 10.1371/journal.pone.0143308

138. Pinker-Domenig K, Tahmassebi A, Wengert G, Helbich TH, Bago-Horvath Z, Morris EA, et al. Abstract 579: magnetic resonance imaging of the breast and radiomics analysis for an improved early prediction of the response to neoadjuvant chemotherapy in breast cancer patients. Cancer Res. (2018) 78:579. doi: 10.1158/1538-7445.AM2018-579
139. Gibbs P, Onishi N, Sadinski M, Gallagher KM, Hughes M, Martinez DF. Characterization of sub- $1 \mathrm{~cm}$ breast lesions using radiomics analysis. J Magn Reson Imaging. (2019) 50:1468-1477. doi: 10.1002/jmri.26732

140. Vidić I, Egnell L, Jerome NP, Teruel JR, Sjøbakk TE, Østlie A, et al. Support vector machine for breast cancer classification using diffusion-weighted MRI histogram features: preliminary study. J Magn Reson Imaging. (2018) 47:1205-16. doi: 10.1002/jmri.25873

141. Xie T, Zhao Q, Fu C, Bai Q, Zhou X, Li L, et al. Differentiation of triplenegative breast cancer from other subtypes through whole-tumor histogram analysis on multiparametric MR imaging. Eur Radiol. (2019) 29:253544. doi: 10.1007/s00330-018-5804-5

142. Pinker K, Chin J, Melsaether AN, Morris EA, Moy L. Precision medicine and radiogenomics in breast cancer: new approaches toward diagnosis and treatment. Radiology. (2018) 287:732-47. doi: 10.1148/radiol.2018172171

143. Lourenco AP, Donegan L, Khalil H, Mainiero MB. Improving outcomes of screening breast MRI with practice evolution: initial clinical experience with 3T compared to 1.5T. J Magn Reson Imaging. (2013) 39:5359. doi: 10.1002/jmri.24198

144. Menezes GLG, Stehouwer BL, Klomp DWJ, van der Velden TA, van den Bosch MAAJ, Knuttel FM, et al. Dynamic contrast-enhanced breast MRI at 7T and 3T: an intra-individual comparison study. SpringerPlus. (2016) 5:13. doi: 10.1186/s40064-015-1654-7

145. van Kalleveen IML, Boer VO, Luijten PR, Klomp DWJ. Tilt optimized flip uniformity (TOFU) RF pulse for uniform image contrast at low specific absorption rate levels in combination with a surface breast coil at 7 tesla. Magn Reson Med. (2015) 74:482-8. doi: 10.1002/mrm.25415

146. Cui J, Bosshard JC, Rispoli JV, Dimitrov IE, Cheshkov S, McDougall MP, et al. A switched-mode breast coil for $7 \mathrm{~T}$ MRI using forced-current excitation. IEEE Trans Biomed Eng. (2015) 62:1777-83. doi: 10.1109/TBME.2015.2403850

147. Cheshkov S, Dimitrov I, Koning W, Rispoli J, McDougall M, Wright S, et al. Integration of 2-channel parallel transmission with forced current excitation for improved $\mathrm{B}_{1}$ homogeneity in breast imaging at 7T. In: Proceedings of the 21st Annual Meeting of ISMRM 2013. Salt Lake City, UT; Concord, CA: iSMRM (2013).p. 4407. Available online at: https://cds.ismrm.org/protected/ 13MProceedings/files/4407.PDF (accessed February 9, 2020).

148. van de Bank B, Voogt I, Italiaander M, Stehouwer BL, Boer VO, Luijten PR, et al. Ultra high spatial and temporal resolution breast imaging at 7T. NMR Biomed. (2013) 26:367-75. doi: 10.1002/nbm.2868

149. By S, Rispoli JV, Cheshkov S, Dimitrov I, Cui J, Seiler S, et al. A 16-channel receive, forced current excitation dual-transmit coil for breast imaging at $7 \mathrm{~T}$. PLoS ONE. (2014) 9:e113969. doi: 10.1371/journal.pone.0113969

150. Kim J, Santini T, Bae KT, Krishnamurthy N, Zhao Y, Zhao T, et al. Development of a 7 T RF coil system for breast imaging. NMR Biomed. (2017) 30:e3664. doi: 10.1002/nbm.3664

151. Krikken E, Steensma BR, Voogt IJ, Luijten PR, Klomp DWJ, Raaijmakers AJE, et al. Homogeneous $\mathrm{B}_{1}^{+}$for bilateral breast imaging at $7 \mathrm{~T}$ using a five dipole transmit array merged with a high density receive loop array. NMR Biomed. (2019) 32:e4039. doi: 10.1002/nbm.4039

152. International Electrotechnical Commission. 60601: Medical Electrical Equipment-Part 2-33 Edition 3.1: Particular Requirements for the Safety of Magnetic Resonance Equipment for Medical Diagnosis. Geneva: IEC (2013).

153. Fiedler TM, Ladd ME, Bitz AK. RF safety assessment of a bilateral four-channel transmit/receive 7 tesla breast coil: SAR versus tissue temperature limits. Med Phys. (2017) 44:143-57. doi: 10.1002/ mp. 12034

154. Li X, Rispoli JV. Toward 7T breast MRI clinical study: safety assessment using simulation of heterogeneous breast models in RF exposure. Magn Reson Med. (2019) 81:1307-21. doi: 10.1002/mrm.27395

155. Li X, Chen X, Steckner M, Rispoli J. An initial simulation study of breast implants for clinical breast MRI. In: Proceedings of the ISMRM 27th Annual Meeting \& Exhibition 2019. Montréal, QC; Concord, CA: ISMRM (2019). p. 1443. Available online at: https://index.mirasmart.com/ ISMRM2019/PDFfiles/1443.html (accessed February 9, 2020).

156. Marino MA, Helbich T, Baltzer P, Pinker-Domenig K. Multiparametric MRI of the breast: a review. J Magn Reson Imaging. (2018) 47:30115. doi: 10.1002/jmri.25790 
157. Weis JA, Miga MI, Arlinghaus LR, Li X, Abramson V, Chakravarthy AB, et al. Predicting the response of breast cancer to neoadjuvant therapy using a mechanically coupled reaction-diffusion model. Cancer Res. (2015) 75:4697-707. doi: 10.1158/0008-5472.CAN-14-2945

158. Leithner D, Wengert GJ, Helbich TH, Thakur S, Ochoa-Albiztegui RE, Morris EA, et al. Clinical role of breast MRI now and going forward. Clin Radiol. (2018) 73:700-14. doi: 10.1016/j.crad.2017. 10.021

159. Canese R, Pisanu ME, Mezzanzanica D, Ricci A, Paris L, Bagnoli M, et al. Characterisation of in vivo ovarian cancer models by quantitative ${ }^{1} \mathrm{H}$ magnetic resonance spectroscopy and diffusion-weighted imaging. NMR Biomed. (2012) 25:632-42. doi: 10.1002/nbm.1779

160. Zhou XJ, Gao Q, Abdullah O, Magin RL. Studies of anomalous diffusion in the human brain using fractional order calculus. Magn Reson Med. (2010) 63:562-9. doi: 10.1002/mrm.22285

161. Bickelhaupt S, Steudle F, Paech D, Mlynarska A, Kuder TA, Lederer $\mathrm{W}$, et al. On a fractional order calculus model in diffusion weighted breast imaging to differentiate between malignant and benign breast lesions detected on X-ray screening mammography. PLoS ONE. (2017) 12:e0176077. doi: 10.1371/journal.pone.0176077

162. Wilson M, Andronesi O, Barker PB, Bartha R, Bizzi A, Bolan PJ, et al. Methodological consensus on clinical proton MRS of the brain: review and recommendations. Magn Reson Med. (2019) 82:527-50. doi: 10.1002/mrm. 27742

163. Taneja S, Jena A, Goel R, Sarin R, Kaul S. Simultaneous whole-body ${ }^{18}$ F-FDG PET-MRI in primary staging of breast cancer: a pilot study. Eur J Radiol. (2014) 83:2231-9. doi: 10.1016/j.ejrad.2014.09.008

164. Melsaether A, Raad RA, Pujara AC, Ponzo FD, Pysarenko KM, Jhaveri $\mathrm{K}$, et al. Comparison of whole-body ${ }^{18} \mathrm{~F}$ FDG PET/MR imaging and whole-body ${ }^{18} \mathrm{~F}$ FDG PET/CT in terms of lesion detection and radiation dose in patients with breast cancer. Radiology. (2016) 281:193202. doi: 10.1148/radiol.2016151155

Conflict of Interest: The authors declare that the research was conducted in the absence of any commercial or financial relationships that could be construed as a potential conflict of interest.

Copyright () 2020 Chhetri, Li and Rispoli. This is an open-access article distributed under the terms of the Creative Commons Attribution License (CC BY). The use, distribution or reproduction in other forums is permitted, provided the original author(s) and the copyright owner(s) are credited and that the original publication in this journal is cited, in accordance with accepted academic practice. No use, distribution or reproduction is permitted which does not comply with these terms. 